\title{
Advances in Inner Magnetosphere Passive and Active Wave Research
}

\author{
James L. Green \\ Space Science Data Operations Office \\ NASA/Goddard Space Flight Center \\ Greenbelt, MD 20771 \\ Shing F. Fung \\ Space Physics Data Facility \\ NASA Goddard Space Flight Center \\ Greenbelt, MD 20771
}

Submitted for Publication in the AGU Monograph on

Physics and Modeling of the Inner Magnetosphere

January 19,2004

Revised June 21, 2004 


\section{ABSTRACT}

This review identifies a number of the principal research advancements that have occurred over the last five years in the study of electromagnetic (EM) waves in the Earth's inner magnetosphere. The observations used in this study are from the plasma wave instruments and radio sounders on Cluster, IMAGE, Getotail, Wind, Polar, Interball, and others. The data from passive plasma wave instruments have led to a number of advances such as: determining the origin and importance of whistler mode waves in the plasmasphere, discovery of the source of kilometric continuum radiation, mapping AKR source regions with "pinpoint" accuracy, and correlating the AKR source location with dipole tilt angle. Active magnetospheric wave experiments have shown that long range ducted and direct echoes can be used to obtain the density distribution of electrons in the polar cap and along plasmaspheric field lines, providing key information on plasmaspheric filling rates and polar cap outflows.

\section{INTRODUCTION}

Within the magnetosphere there are more then 40 plasma wave emissions that have been classified (see the excellent review by Shawhan,1979). It is well known that space plasmas can support a variety of EM wave modes. To illustrate, Figure 1 shows various propagation modes for a point in the inner magnetosphere (at radial distances less than geosynchronous) in which the local electron gyrofrequency is less than the local electron

plasma frequency $\left(f_{g}<f_{p}\right.$; i.e. the plasmasphere). As the frequency increases (from $\mathrm{Hz}$ to $\mathrm{kHz}$ ) plasma waves can propagate in the whistler, $\mathrm{Z}$, and the $\mathrm{L}-\mathrm{O}$ and $\mathrm{R}-\mathrm{X}$ modes. The frequency range of each mode has been shaded to easily distinguish between them.

These modes have lower and, sometimes, upper frequency limits to their propagation that are called cutoffs or resonances as described by Stix [1992]. The left hand ordinary (L-O) and the right-hand extraordinary (R-X) modes are called the free space modes (using the terminology of Stix, 1992) since they only have lower frequency cutoffs ( $f_{R}$ for $R-X$ mode and $\mathrm{f}_{\mathrm{p}}$ for L-O mode as shown in Figure 1) and at sufficiently high frequencies can 
propagate into the solar wind once they are generated in the magnetosphere. The $\mathrm{Z}$ and whistler mode emissions are referred to as trapped emissions since they have well defined upper frequency limits that confine these emissions to specific regions in space.

Due to space limitations it is impossible to review all the progress made in understanding magnetospheric processes from EM waves, so the authors will concentrate on a few selected topics that have undergone rapid advances in the last five years in both trapped and free space portions of the spectrum. Recent missions such as Cluster and IMAGE, along with older missions such as Geotail, Wind, Polar, and Interball that routinely orbit the Earth, have provided a wealth of new data for analysis. In addition to passive measurements, the long range EM sounder capability on IMAGE and the short-range sounders on the four Cluster spacecraft are producing unique types of data. The purpose of this paper is to review a number of important advances in our understanding of inner magnetospheric processes from passive and active wave measurements. The paper will first concentrate on passive measurements consisting of trapped emissions (Section 2) and escaping emissions (Section 3 ) and then on active magnetospheric sounder measurements (Section 4).

\section{TRAPPED EMISSIONS IN THE PLASMASPHERE}

The index of refraction in the whistler mode is such that some of these EM waves have a natural tendency to travel along a magnetic field. In the plasmasphere, whistler mode waves make repeated journeys from northern to southern hemisphere and vice versa. Since the upper frequency of the whistler mode is the local $f_{p}$ or $f_{g}$ (see Figure 1) whichever is less, these waves are largely confined or trapped in the higher density plasmasphere region around the Earth.

There are four basic whistler mode waves generated in the plasmasphere as summarized in Figure 2 as a function of their frequency range. From $10-50 \mathrm{kHz}$, Earth-based transmitters dominate the spectrum. The authors have identified over 100 stations generating emissions at more than 60 discrete frequencies, and there are quite likely 
many more. Chorus emissions, observed just outside the plasmasphere typically in the frequency range from $0.3-12 \mathrm{kHz}$, can be found extending from the magnetic equator to mid-latitudes, and generally intensify during storm periods. Plasmaspheric hiss is observed in the plasmasphere at frequencies typically between $0.3-3 \mathrm{kHz}$ and is believed to be responsible for electron precipitation in the slot region ( $L \sim 2.5)$ between the inner and outer radiation belts. Electromagnetic (EM) equatorial waves are typically found from a few $\mathrm{Hz}$ to about $300 \mathrm{~Hz}$ and are confined to the magnetic equator (typically within $1 R_{E}$ ) within the plasmasphere. Lightning whistlers are also observed in the plasmasphere (not shown in Figure 2) and they have the frequency range of from about 0 to $10 \mathrm{kHz}$.

The average magnetic wave field spectral density measurements, as a function of frequency and L value, from the Plasma Wave Instrument (PWI) on Dynamics Explorer 1 (hereafter DE) is shown in Figure 3 [adapted from André et al., 2002]. The top and bottom panels of Figure 3 are from quiet and disturbed conditions respectively, use the same intensity levels, and show the dramatic increase in intensity of the whistler mode wave spectrum in the plasmasphere (except for the transmitters) during disturbed conditions. The longitudinal distributions, where the whistler mode waves-are the most intense in the plasmasphere, are shown in Figure 4. Most of the whistler mode wave research in the last 5 years has dealt with various aspects of plasmaspheric hiss and chorus. Resent results of plasmaspheric hiss research will be discussed in this review since chorus is well covered by another paper in this monograph [see Meredith et al., 2004].

\subsection{PLASMASPHERIC HISS}

Although found essentially everywhere in the plasmasphere at some intensity level, plasmaspheric hiss is most intense throughout the local afternoon sector (see Figure 4) and on $\mathrm{L}$ shells which contain the slot region in the electron radiation belts. The origin of this emission is still somewhat controversial as either generated by gyroresonance or by lightning. Research in this area over the last 5 years supports the idea that plasmaspheric 
hiss is an accumulation of many whistlers trapped in the plasmasphere, but the relative contribution from different sources is still unknown.

The classic theoretical work by Kennel and Petschek [1966] held that plasmaspheric hiss receives its energy from a gyroresonance interaction with inner radiation belt electrons near the magnetic equator causing the electrons to change pitch angle and precipitate, generating the electron slot region between the inner and outer belts. The theory states that the amplification of the emission is maximized when the wave normal angle (WNA), which is the angle between the wave's phase velocity ( $\mathrm{k}$ vector) and the local magnetic field, is near $0^{\circ}$. The amplification expected, however, was only a few $\mathrm{dB}$ and well below the observed intensities of hiss (see Figure 3). Thorne et al. [1979] suggested that plasmaspheric hiss would only grow in intensity from the background thermal noise to its observed intensity from gyroresonance acceleration as the whistler mode wave returned through the equator repeatedly. This idea would also require the waves to maintain a near parallel WNA. More recently, Able and Thorne [1998] have suggested that this would happen if the hiss would suffer reflection from the plasmapause at mid or higher latitudes during its inter-hemisphere trajectory. But, this idea is not universally held since Storey et al. [1991] observed hiss propagating at large WNA even in the equatorial region.

Using the wave distribution function technique developed by Storey and Lefeuvre [1979], Santolik et al. [2001] found that most of the observed waves on $L$ shells above 3 had WNA nearly parallel to the Earth's magnetic field, while others had oblique WNAs. In addition, these authors found evidence of wave amplification near the geomagnetic equator supporting the theories by Kennel and Petschek [1966] and Thorne et al., [1979].

Bortnik et al., [2003] have found that the lightning generated whistlers tend to settle on preferred L-shells in the plasmasphere with the lower frequency components settling at higher L-shells and higher frequency components on lower L-shells. These whistlers are referred to as magnetospherically reflected since they do not bounce off the plasmapause but are internally reflected within the plasmasphere. By combining the lightning, 
whistler lifetimes with the power spectral density of lightning Bortnik et al. [2003] showed a clear maximum in wave energy in the slot region at about an $\mathrm{L}$ of 2 .

Rodger et al. [2003] extended these results and determined, from modeling calculations, that electrons in the $\sim 50$ to $150 \mathrm{keV}$ range precipitate out of the slot region $(\mathrm{L}=2-2.4)$ through gryoresonance interaction with lightning generated whistlers. For electron energies above this range, Rodger et al. [2003] believes that ground-based transmitters and plasmaspheric hiss should dominate over all other loss processes.

\section{CONTINUUM RADIATION}

The Earth's nonthermal continuum radiation is observed over a very broad frequency range from as low as $5 \mathrm{kHz}$ [Gurnett, 1975] to as high as $800 \mathrm{kHz}$ [Hashimoto et al., 1999] and is generated in the free space L-O mode above the local $f_{p}$ from sources at or near the plasmapause [Gurnett et al., 1988]. In the last 5 years, research in continuum radiation has focused on improving our understanding of the source location, emission cone characteristics, and detailed spectral measurements. Much of what has emerged from these studies in terms of source location is summarized in Figure 5. The lower frequency trapped and escaping continuum is generated in the pre-noon section (also called normal continuum), the continuum enhancement is generated in the morning sector, and the kilometric continuum is generated in deep plasmaspheric notch structures. These emissions will be discussed below.

Continuum radiation has been shown to be closely associated with strong narrow-band electrostatic emissions at the plasmapause at the magnetic equator [Kurth et al., 1979]. These strong electrostatic bands occurs at frequencies where the frequency of the electrostatic upper hybrid resonance $\left(f_{\text {urr }}\right)$ is equal to the frequency of the electrostatic $(n+1 / 2) f_{g}$ resonance. It is believed that continuum radiation is generated by a mode conversion process, converting electrostatic $Z$ mode emissions to the electromagnetic $\mathrm{L}$ $O$ mode, over the entire frequency range of the emission (see Figure 1). The two classes 
of mode conversion mechanisms that have been considered are linear [e.g., Jones, 1976 .

and Budden, 1980] and non-linear [e.g., Melrose, 1981; Fung and Papadopoulos, 1987].

\subsection{NORMAL CONTINUUM RADIATION}

At frequencies less than the magnetopause plasma frequency $(\sim 30 \mathrm{kHz})$, the continuum radiation has been referred to as the "trapped" component [Gurnett and Shaw, 1973] since it is observed primarily in the magnetospheric density cavity between the plasmapause and magnetopause (see an example in Figure 5). The trapped continuum spectrum is observed as a broad-band emission with very little frequency structure. The broad-band structure of the trapped continuum spectrum is believed to be produced from a series of narrow band emissions at slightly different frequencies from an extended source region at the plasmapause whose emission then mixes due to multiple reflections (with some Doppler broadening) in the magnetospheric density cavity.

Continuum radiation at frequencies above the magnetopause plasma frequency has been referred to as the "escaping" component [Kurth et al., 1981] since it propagates from the Earth's plasmapause to well outside the magnetosphere (see an example in Figure 5). A common characteristic of all the escaping continuum radiation is that it has narrow frequency bands of emissions showing that the name continuum is not entirely descriptive of the radiation in this frequency range. Continuum radiation below $100 \mathrm{kHz}$ is typically generated at the plasmapause in the pre-noon sector (06-12 LT) and has been called "normal continuum" by a number of authors [e.g., Kasaba et al., 1998; Hashimoto et al., 1999].

Figure 6 has been adapted from Plate 3 and Figure1 of Green and Boardsen [1999] and shows the observed emission cone of the normal continuum radiation by combining four years of Hawkeye plasma wave data overlaid with ray tracing calculations at that same frequency. These authors found that normal continuum radiation was generated in the pre-noon sector and is beamed into broad cones (half width of $\sim 35^{\circ}$ ) at low frequencies $(\sim 30 \mathrm{kHz})$. When modeled with ray tracing calculations, the resulting radiation pattern is 
such that the trapped continuum radiation does not completely fill the magnetospheric cavity as previously believed. In addition, the trapped continuum component that consists of multiple reflections between the magnetopause and the plasmapause, as shown in Figure 6 (labeled as "trapped rays"), is confined to only $\sim 10^{\circ}$ in latitude about the magnetic equator.

Direction finding measurements from all four of the Cluster spacecraft from spin modulated Whisper data have confirmed many of the general properties of continuum radiation such as the plasmapause source regions [see Décréau et al., 2004]. Near source region measurements have revealed new properties such as the importance of small-scale density irregularities in the local amplification of normal continuum and the possible role wave ducting may play in its generation.

Normal continuum radiation at frequencies near the magnetopause plasma frequency has also been used to be an indicator of the global scale magnetosheath electron density. Nagano et al. [2003], using data from PWI on Geotail, observed a portion of the normal continuum spectrum that was trapped within the magnetsheath. The upper frequency was controlled by the $f_{p}$ in the solar wind after taking into account a time delay. The upper frequency was termed the transition frequency since it was the frequency at which the radiation changed from isotropic (due to multiple reflections in the magnetosheath randomizing its direction of arrival) to anisotropic (having a preferred direction). These authors found that a 0-3 hour time delay in the variation in the transition frequency of the normal continuum relative to the upstream $f_{p}$ may suggest that the magnetosheath plasma relaxes at the local Alfven speed rather than the convection speed of the solar wind.

\subsection{CONTINUUM ENHANCEMENT}

Large variations in continuum intensity over the $20-80 \mathrm{kHz}$ frequency range lasting for up to 2 hours have been observed primarily in the midnight to dawn sector and were first reported by Gough [1982]. This distinct feature in the continuum emission spectrum has been called "continuum enhancement" by Kasaba et al. [1998]. The characteristic 
emission spectrum of continuum enhancement is shown in the upper left spectrogram panel of Figure 5. Kasaba et al. [1998], using simultaneous Geotail and Wind observations, showed that the normal continuum emissions in the pre-noon sector appeared to follow continuum enhancement events. This relationship has lead these authors to suggest that a series of storm time electron injections are generating both types of emissions.

\subsection{KILOMETRIC CONTINUUM}

Kilometric continuum $(\mathrm{KC})$ is a major component of the escaping continuum radiation in the $100-800 \mathrm{kHz}$ frequency range. Hashimoto et al. [1999] have rediscovered this component of the emission and has sparked considerable interest in further understanding various aspects of this radiation that make it different from its lower frequency trapped and escaping $(<100 \mathrm{kHz})$ counterpart generated in the pre-noon sector and discussed in the previous section. The lower right hand panel of Figure 5 clearly shows the discrete emissions bands of KC extending from 17-24UT. The frequency range for kilometric continuum is approximately the frequency range of auroral kilometric radiation (AKR), but as shown in the lower right hand panel of Figure 5, there are significant differences that can be used to easily distinguish between these two emissions. $\mathrm{KC}$ has a narrow band structure over a number of discrete frequencies while AKR is observed to be a broadband and sporadic emission and can be seen from 16-17:00 and from 21:30 to 24:00 UT in that spectrogram.

Kilometric continuum has been observed at all local times, although it has been difficult to make a positive identification of the emission during the times when Geotail was in the late evening or early morning local time sector when AKR was active [Hashimoto et al., 1999]. From Geotail and IMAGE observations Hashimoto et al. [1999] and Green et al. [2004a] have found that kilometric continuum is confined to a narrow latitude range of approximately $\square 15^{\circ}$ about the magnetic equator. Although these characteristics make it different from the lower frequency continuum discussed in Section 3.2, the similar spectral characteristics of the emission and its relationship to the plasmapause supports 
the conclusion by Menietti et al. [2003] from Polar observations that the radiation is generated by the same mechanism.

At lower frequencies, beaming of continuum radiation around the magnetic equator to latitudes as high as $50^{\circ}$ has also been observed by Jones et al. [1987] (from 80 to 100 $\mathrm{kHz}$ ), Morgan and Gurnett [1991] (from 45 to $154 \mathrm{kHz}$ ), and by Green and Boardsen [1999] (from 24 to $56 \mathrm{kHz}$ ) as discussed above. The narrow beaming of kilometric continuum in magnetic latitude has made this emission difficult to observe routinely or for only short periods of time except for equatorial orbiting spacecraft with the proper instrumentation, such as Geotail.

The source region for $\mathrm{KC}$ was originally identified by Carpenter et al. [2000] as coming from plasmaspheric cavities, but more recently Green et al. [2002] and Green et al. [2004a] clearly identified $\mathrm{KC}$ as being generated at the plasmapause, deep within notch structures that corrotate with the Earth. Figure 7 has been adapted from Figure 8 of Green et al. [2002] and Figure 1 of Green et al. [2004a] and illusträtes the location of the $\mathrm{KC}$ source region and resulting emission cone pattern of the radiation to be consistent with the observations. Panel A of Figure 7 is a frequency-time spectrogram from the PWI instrument on GEOTAIL showing the banded structure of KC. Panel B shows the magnetic longitude versus the equatorial radial distance of the plasmapause (derived from the inserted EUV image of the plasmasphere) and the position of GEOTAIL during the $\mathrm{KC}$ observations of panel $\mathrm{A}$. Panel $\mathrm{C}$ is a ray tracing analysis which shows that the structure of the plasmaspheric notch has a significant effect on the shape of the resulting emission cone through refraction. The process by which the notch structure is produced in the plasmasphere is not completely understood at this time.

\subsection{AURORAL KILOMETRIC RADIATION}

Over 35 papers have been published in the last 5 years on auroral kilometric radiation (AKR) demonstrating that after the classic paper by Gurnett [1974], AKR is, arguably, still the most intensely studied magnetospheric emission. It is beyond the scope of this 
brief review to discuss all these results. Significant progress in understanding various aspects in the generation of AKR has been made in the areas of seasonal and solar cycle variations, polarization measurements, fine structure, and source region location. AKR research continues to be an important aspect of ionospheric-magnetospheric coupling during the substorm processes.

The cyclotron maser instability [Wu and Lee, 1979] is believed to be the basic mechanism for the generation of AKR. For generation of AKR near the local electron gyrofrequency, the cyclotron maser instability requires a source of free energy in the electron distribution and the following condition:

$$
\mathrm{f}_{\mathrm{p}} / \mathrm{f}_{\mathrm{g}}<0.3
$$

The observation that the AKR emission frequency is very near the local $f_{g}$ in the auroral zone density cavity [e.g., Hilgers et al., 1991] where the electron distribution function has a number of sources of free energy [Delory et al., 1998; Ergun et al., 1998; Ergun et al., 2000; Fung and Vinas, 1994] is the strongest observational evidence supporting the cyclotron maser instability.

The AKR emission spectrum, in general terms, is observed over a broad frequency range from $\sim 30$ to $\sim 700 \mathrm{kHz}$ with the peak intensity around $250 \mathrm{kHz}$. Kumamoto and Oya [1998] noted a seasonal difference in the AKR intensity from Akebono plasma wave data with increases in intensity in the winter polar region over the summer polar region. Kumamoto et al. [2003] expanded on these results and showed seasonal and solar cycle variations in the vertical distribution of the occurrence probability of AKR emissions from low altitude Akebono measurements. Using Polar and IMAGE wave data, Green et al. [2004b] used the observed AKR spectrum to estimate the altitude range of the source region as suggested by Lee et al. [1980] by mapping the observed frequency to the $f_{g}$ in the auroral density cavity. In both these studies, ionospheric density variations were believed to be mainly responsible for large-scale changes in the AKR source location. 
Using two years of IMAGE RPI and one and a half years of Polar PWI data Green et al. [2004b], found a dramatic frequency shift in the average AKR spectrum (intensity normalized to $8 \mathrm{R}_{\mathrm{E}}$ ) with dipole tilt. Panel A of Figure 8 clearly shows two main seasonal effects on the average AKR spectrum as observed by the IMAGE RPI instrument: 1) the AKR emission spectrum shifts down in frequency with increasing dipole tilt, and 2) the emission spectrum extends over a larger frequency range for negative dipole tilt angles than for positive dipole tilt angles. Panel B of Figure 8 is a qualitative illustration of the AKR spectrum, from panel $A$, mapped into contours of $f_{p} / f_{g}$ for a $70^{\circ}$ invariant auroral field line. Green et al. [2004b] found that the source region during extreme negative dipole tilt angles (winter) shows the auroral zone density cavity stretching from a region where $\mathrm{f}_{\mathrm{g}}=500 \mathrm{kHz}$ to nearly $\mathrm{f}_{\mathrm{g}}=80 \mathrm{kHz}$. In contrast, for extreme positive dipole tilt angles the source region extent is much smaller, has moved further up the field line, and has a lower frequency boundary of $60 \mathrm{kHz}$ and an upper frequency boundary near 250 $\mathrm{kHz}$. In addition, Green et al. [2004b] also found an overall solar cycle effect with the average AKR intensity lowered by as much as an order of magnitude during solar maximum. These results are consistent with Newell et al., [1996] who showed that there is a significant suppression of discrete aurora by sunlight and that ionospheric conductivity is a key factor in controlling the occurrence of discrete aurora. It was Gurnett [1974] who first clearly showed that AKR was closely correlated with discrete auroral arcs.

The Polrad instrument on Interball 2 has made detailed polarization measurements of AKR distinguishing between $\mathrm{L}-\mathrm{O}$ and R-X polarization components. Figure 9, adapted from Hanasz et al. [2003], show a frequency time spectrogram of AKR from Polrad (top panel) and the polarization (middle panel) derived from determining the Stokes parameters [technique described by Hanasz et al., 2000] and by factoring in the trajectory of the spacecraft relative to the source region (bottom panel). Hanasz, et al. [2003] has found that L-O polarized AKR, observed to be coming from dayside sources, is about three times more frequent than L-O polarized nightside sources which are observed about $10 \%$ of the time. In addition, Hanasz et al. [2003] was able to distinguish two classes in the circular polarized AKR spectrum. The "regular" AKR is dominated by the R-X mode 
and observed in the upper frequency portion of the spectrum and a weak L-O mode in the lower portion as shown in Figure 9. The "irregular" AKR is somewhat patchy with the two polarizations interwoven randomly over the whole frequency range. The reason for this variation in polarization is unknown.

Another new spectral feature of AKR recently discovered by de Feraudy et al. [2001] and Hanasz et al. [2001] is an intense, nearly simultaneous broad frequency burst of AKR in as short as $6 \mathrm{~s}$ and as long as a few minutes that is generated during the fast expansion of the auroral bulge. These bursts of emission extend from 100 to $800 \mathrm{kHz}$ and last for only a few tens of minutes. What remains to be explained is how the free energy for these waves be created so rapidly along such a large section of the source field line.

The AKR emission spectrum also contains narrow band fine structure referred to as striations. Menietti et al. [2000] have analyzed a semi-random sample of the AKR spectrum using the high-resolution wideband instrument on the Polar satellite. New results from that survey show that the AKR fine structure, consisting of very narrow band emissions, is observed predominantly in the $40-215 \mathrm{kHz}$ range and drifts in frequency with time. Negative drifting fine structures bands (decreasing frequency with time) are observed approximately $6 \%$ of the time, while the positive sloping (increasing in frequency with time) striations are observed at a much lower rate. The typical drift rate of the fine structure is observed to be between $-8 \mathrm{kHz} / \mathrm{s}$ and $-2 \mathrm{kHz} / \mathrm{s}$ and, for the positive sloping fine structure, between 5 or $6 \mathrm{kHz} / \mathrm{s}$. In addition, there was a general decrease in drift rate with increasing frequency. Although the origin of the AKR fine structure is not known, it has been pointed out that the frequency dependence of the drift rate is consistent with AKR production stimulated by an upward propagating electromagnetic ion cyclotron wave [Menietti et al., 1996].

Applying a very long baseline interferometry (VLBI) technique to simultaneous observations from the four Cluster spacecraft, Mutel et al. [2003 and 2004] determined the source locations, at selected frequencies, of individual AKR bursts. The VLBI 
technique involves precise timing of measured wave fronts from two or more locations separated by great distances. Six baselines can be formed from the four spacecraft yielding, when combined with the knowledge that the AKR emission is very close to the local gyrofrequency in the source region, source positions within an error of $\sim 200 \mathrm{~km}$ from individual burst events. From several thousand observed burst events, Mutel et al. [2003] found that the AKR sources were confined to the nightside auroral oval and that the distribution of AKR auroral source footpoints, during the same storm period (1-3 hours long), had an overall spatial scale from 1000 to $2000 \mathrm{~km}$. This is entirely consistent with a number of other earlier studies [e.g., Kurth et al., 1975; Gallagher and Gurnett, 1979; and Panchenko, 2003]. As an example of the "pin-point" accuracy that this new technique has yielded, Figure 10 shows source locations from AKR burst at $125 \mathrm{kHz}$ (red), 250 (green), and $500 \mathrm{kHz}$ (blue) from two substorms. Panel A shows AKR burst locations during a southern hemisphere (positive dipole tilt) pass while panel $B$ show the sources from a northern hemisphere (negative dipole tilt) pass. A clear shift in local time in AKR source region extent is seen in Figure 10 which is consistent with the results by Green et al. [2004b] that AKR sources are near dusk during times of positive dipole tilt and near midnight during times of negative dipole tilt. This effect is attributed to AKR source regions preferring the lower density cavity regions that develop along field lines whose foot is not illuminated by the sunlight. During times of negative dipole tilt a greater portion of the auroral oval is in darkness (AKR sources found near the dusk or late afternoon) with the opposite effect occurring during times of positive dipole tilt (AKR sources more towards midnight). It is important to point out that seasonal variations in the production of AKR were also found in an earlier study by Kasaba et al, [1997] from GEOTAIL/PWI observations. These authors showed that AKR is more active in the winter hemisphere for higher frequencies $(500 \mathrm{kHz})$ representing lower latitude source regions.

\section{ACTIVE PROBES}

Plasma waves offer invaluable means for probing remote plasma regimes that are not readily or conveniently accessible to in situ measurements. Using the propagation 
characteristics such as cutoffs and resonances of different wave modes [Stix, 1992], it is possible to ascertain plasma environment parameters, such as density and magnetic field strength profiles, with accuracies that rival or are even superior to those measured by in situ instrumentations. An advantage of active probing by plasma waves over conventional passive observation techniques is that a large volume of the target plasma regime can be probed simultaneously. In this section, we review recent advances in active remote sensing of magnetospheric plasmas.

\section{I BRIEF HISTORICAL DEVELOPMENT}

The earliest applications of active probing of space plasmas were soundings of the ionosphere by radio waves [Appleton and Barnett, 1925; Breit and Tuve 1926]. In fact, much of our current knowledge about the structures of the ionosphere has been derived from active radio measurements [e.g., Davies, 1990; Hunsucker, 1992]. Because of ionospheric shielding, ground-based radio observations of the magnetosphere are not possible except by whistler waves [Storey, 1953; Helliwell, 1988.]: Nevertheless, active magnetospheric sounding has been proposed for many years [Franklin and Maclean, 1969; Ondoh et al., 1978; Calvert, 1981]. Because of the long ranges and uncertainties involving magnetopspheric plasma targets, the practicality of magnetospheric radio sounding had been subject of investigations [Green et al., 1993; Calvert et al., 1995; Calvert et al., 1997; Greenwald, 1997a,b]. The first successful long-range magnetospheric sounder experiment is the Radio Plasma Imager (RPI) [Reinisch et al., 2000] aboard the Imager for Magnetopause-to-Aurora Global Exploration (IMAGE) satellite [Burch, 2000], launched on March 25, 2000.

\subsection{ACTIVE RADIO TECHNIQUES}

Active probing by radio waves involves transmitting radio waves into a plasma target, and receiving the signals (echoes) returned after the incident waves interacted with the target. Classification of different probing techniques depends on the mechanisms by which signals are returned to the receivers, and thus on the frequencies of the probing 
waves. The instrument that performs active radio probing of plasmas is called a sounder or radar.

\subsubsection{INCOHERENT SCATTERING}

As mentioned above, radio probing has been used most extensively in ionospheric studies. Notable instrumentations used in these studies include bottom-side (ionosondes) and topside (space-based) radio sounders, and incoherent and coherent scatter radars [Kelley, 1989]. An incoherent scatter radar (ISR) operating at high frequencies $(>$ few hundred MHz) transmits waves with wavelengths that are typically small compared to the Debye length, $\lambda_{\mathrm{De}}=\mathrm{v}_{\mathrm{e}} / f_{\mathrm{p}}$ (where $\mathrm{v}_{\mathrm{e}}$ is the thermal speed and $f_{\mathrm{p}}$ is the plasma frequency) of the intervening medium and the target plasma. The ISR-transmitted waves can therefore interact with individual charged particles and thus be Thomson scattered, i.e., absorbed and re-radiated. A small amount of the scattered wave energy can always return to the receiver as echoes. Signals from different ranges can be selected by different delay times. The ISR turns out to be a very useful tool for studying the ionosphere above the $\mathrm{E}$ and $\mathrm{F}$ layers where the densities are higher than the densities in the layers above.

It should be noted, however, that when ISR was first constructed to observe the ionosphere, the detected signal strengths were found to be much stronger and concentrated in much narrower bandwidths than expected from incoherent backscattering [Bowles, 1958]. It was then found that the observed scattered signals at frequencies $<$ few $100 \mathrm{MHz}$ were due to backscattering from ion acoustic waves, a process that is more akin to coherent scattering to be discussed next [e.g., Dougherty and Farley, 1960].

\subsubsection{COHERENT SCATTERING}

Ionospheric and magnetospheric plasmas are filled with irregularities of various scale sizes [e.g., Fejer and Kelley, 1980; Hanuise, 1983; Fung et al., 2000; Fung et al., 2003]. When the wavelengths of the probing radio waves are larger than the local Debye length 
and become comparable to certain plasma irregularity scales, the waves can be effectively scattered by plasma collective effects according to

$$
\mathbf{k}_{\mathrm{i}}=\mathbf{k}_{\mathrm{s}}+\mathbf{k}_{\mathrm{ir}}
$$

where $\mathbf{k}_{\mathrm{i}}, \mathbf{k}_{\mathrm{s}}$, and $\mathbf{k}_{\mathrm{ir}}$ are the incident, scattered, and plasma irregularity wave vector, respectively. A special case of coherent scattering of this type is backscattering, in which $\mathbf{k}_{\mathrm{s}} \approx-\mathbf{k}_{\mathbf{i}}$, so that equation (2) gives $\mathbf{k}_{\mathrm{ir}} \approx 2 \mathbf{k}_{\mathrm{i}}$. This is the well-known aspect-sensitive backscattering condition that the scattering irregularity scale is half the probing wavelength. Coherent scatter radars (CSR) and aspect-sensitive scattering are particularly useful for measuring the occurrences of plasma instabilities and determining plasma irregularities, such as spread F [Fejer and Kelley, 1980; James, 1989].

\subsubsection{RELAXATION SOUNDING}

Like any object, a plasma has a number of "ring tones" or resonances that are characteristic of the plasma density and embedded magnetic field strength. Plasma resonances have been explained in terms of sounder-stimulated electrostatic waves that propagate to short distances from the sounder and are reflected by local gradients back to the sounder receiver [Muldrew, 1972]. To learn about the local properties of a plasma medium, a relaxation sounder can be used to send out small amount of wave energy to stimulate resonances in the plasma nearby to the sounder [e.g., Etcheto and Bloch, 1978; Etcheto et al., 1983; Trotignon et al., 1986; Oya and Ono, 1987; Oya et al., 1990]. This technique has been used by the Alouette-ISIS topside sounder satellites [Jackson, 1986] to produce many valuable studies of ionospheric resonances [e.g., Benson, 1971; 1977; 1996; Warnock, 1969; Warren and Hagg, 1968; Muldrew, 1972]. Typical plasma resonances observed in the ionosphere and magnetosphere include the electron gyroharmonic resonances $\mathrm{n} f_{\mathrm{g}}$, electron plasma resonance $f_{\mathrm{p}}$, and the upper hybrid resonance $f_{\text {uhr }}$,

$$
f_{\mathrm{g}}(\mathrm{kHz})=0.028 \mathrm{~B}(\mathrm{nT})
$$




$$
\begin{aligned}
& f_{\mathrm{p}}(\mathrm{kHz}) \approx 8.97\left[\mathrm{~N}_{\mathrm{e}}\left(\mathrm{cm}^{-3}\right)\right]^{1 / 2} \\
& f_{\mathrm{uhr}}=\left(f_{\mathrm{g}}{ }^{2}+f_{\mathrm{p}}{ }^{2}\right)^{1 / 2}
\end{aligned}
$$

As shown in Benson et al. [2003], gyroharmonic and other plasma resonances [(4) and (5)] are useful for deriving local magnetic field strengths and densities (to within a few percent), particularly when there is no other in situ observations of such parameters.

In addition, there exist " $(n+1 / 2) f_{g}$ " resonances that occur between successive gyroharmonics and have been referred to as the $Q_{n}$ and $D_{n}$ resonances, depending on whether they are observed above or below the upper hybrid resonance $f_{\text {uh }}$ [equation (5)] [e.g., Benson et al., 2003]. Assuming a thermal electron plasma distribution, Warren and Hagg [1968] obtained an expression for the $Q_{n}$ frequencies,

$$
f_{\mathrm{Qn}}=f_{\mathrm{g}}\left[\mathrm{n}+\left(0.464 / \mathrm{n}^{2}\right)\left(f_{\mathrm{P}} / f_{\mathrm{g}}\right)^{2}\right]
$$

For $\mathrm{n} \geq 1$, the $\mathrm{Q}_{\mathbf{n}}$ resonances can be weak and not easily distinguishable from gyroharmonic resonances when $\left(f_{\mathrm{p}} / f_{\mathrm{g}}\right)^{2}<1$ [Perraut et al., 1990]. Frequency splitting of $\mathrm{Q}_{\mathrm{n}}$ resonances has also been observed [e.g., Trotignon et al., 1986; Canu et al., 2001; Trotignon et al., 2001].

The identification and interpretation of magnetospheric $D_{n}$ resonances has been somewhat controversial [LeSager et al., 1998; Benson et al., 2001; Canu, 2001a,b]. $\mathrm{D}_{\mathrm{n}}$ resonances were first identified in topside ionospheric sounding data [Nelms and Lockwood, 1967; Oya, 1970], but there had not been any first-principle explanation for their mode of propagation. Osherovich [1987; 1989] and Osherovich and Benson [1991] have found, however, the eigen-frequencies derived from an electromagnetic force-free analysis of a cylindrical plasma volume to match the observed $D_{n}$ resonances quite successfully, yielding 


$$
\begin{aligned}
& f_{\mathrm{Dn}}=0.95\left(f_{\mathrm{g}} f_{\mathrm{p}}\right)^{1 / 2} \mathrm{n}^{1 / 2} \\
& f_{\mathrm{Dn}}{ }^{+}=\left(f_{\mathrm{Dn}}{ }^{2}+f_{\mathrm{g}}^{2}\right)^{1 / 2} \\
& f_{\mathrm{Dn}}{ }^{-}=\left(f_{\mathrm{Dn}}{ }^{2}-f_{\mathrm{g}}\right)^{1 / 2}
\end{aligned}
$$

While equations (7)-(9) seem to allow an independent means to determine the local $f_{\mathrm{g}}$ and $f_{\mathrm{p}}$, particularly when the plasma and gyroharmonic resonances are not otherwise observed, their origin remain to be explained theoretically based on realistic plasma distributions.

\subsubsection{LONG-RANGE SOUNDING}

As implied by its name, long-range (LR) sounding uses radio waves to probe plasma regimes at a distance. This differs from the other techniques mentioned so far in that target ranges in $L R$ sounding can be more than an Earth radius $\left(1 R_{E} \approx 6378 \mathrm{~km}\right)$. The long sounding ranges would normally require higher transmission powers to overcome the long distances. Special digital techniques, such as pulse compression and spectral integration, however, are used by RPI on IMAGE to lower the transmission power requirements so that $L R$ sounding of the magnetosphere can become possible [Benson et al., 1998; Reinisch et al., 2000].

After a sounder pulse is transmitted, different types of echoes are received, depending on the structure of the medium and irregularities present in the target region [Fung et al., 2000]. Figure 11 illustrates the different types of possible echoes from a magnetospheric sounder. As discussed above, short-range echoes from local resonances (e.g., $f_{\mathrm{p}}$ and $\mathrm{n} f_{\mathrm{g}}$ ) are due to electrostatic waves excited by the sounder pulse [Muldrew, 1972; Benson et al., 2003 and references therein]. In LR magnetospheric sounding, due to the generally low transmission power involved, only specularly reflected or coherently backscattered 
signals are detectable over long distances. Incoherent scatter signals are too weak to be observed.

Radio waves transmitted at frequencies above the local cutoffs $\left(f_{\mathrm{R}}\right.$ or $f_{\mathrm{P}}$, see Figure 1) can propagate freely in all directions. When the wave propagates into a refractive index gradient (due to density or magnetic field increases), its wavelength will increase until it reaches a cutoff where the wave frequency matches the local cutoff frequency, and the refractive index vanishes $(\mathrm{k}=0)$. The wave will then be reflected [Stix, 1992]. According to the law of reflection and the wave-path reciprocity theorem [Born and Wolf, 1999], only waves propagating parallel to the refractive index gradient $(\mathbf{k} \| \nabla \mathbf{n})$ will return to the sounder (receiver) location.

If the target plasma has a smooth gradient with a scale length $L_{n, B} \gg \lambda$ and is free of small-scale $\left(\lambda_{\mathrm{ir}}<\lambda\right)$ irregularities, then the incoming sounder waves will be specularly reflected at a cutoff $\left(f_{R}\right.$ for R-X mode and $f_{p}$ for L-O mode as shown in Figure 1). The wave cutoffs are related to the local electron plasma density and magnetic field conditions, echoes of the sounder waves then yield important information on the remote target region. L-O mode echo frequencies yield remote density information directly. Since the R-X mode cutoff depends on both the electron density and magnetic field strength, estimates of remote densities can be obtained from R-X mode echoes if the magnetic field strengths at the remote sites can be determined from magnetic field models. The total time delay $\tau$ of an echo then yields the so-called virtual range $\left[R_{V}=\right.$ $c \tau / 2]$ of the reflection point, which assumes that the propagation speed throughout is the vacuum speed of light $c$. Techniques are available to invert the frequency-versus-virtual range observations into density profiles of the target plasma [e.g., Jackson, 1969; Huang and Reinisch, 1982; Reinisch et al., 2001a].

On the other hand, if there are small-scale irregularities in the target region, then different frequency waves can be coherently backscattered wherever the $\mathbf{k}_{\mathrm{ir}} \approx 2 \mathbf{k}_{\mathrm{i}}$ condition is satisfied. The fact that the backscattering condition can be satisfied at different points in the target region means that there would be range spreading in the received echoes. In 
addition, if the irregularities have both spatial and temporal variations $\left(f_{\mathrm{ir}}, \mathbf{k}_{\mathrm{ir}}\right)$, then analogous to equation (2) the scattered waves will also exhibit frequency spreading according to

$$
f_{\mathrm{i}}=f_{\mathrm{s}}+f_{\mathrm{ir}}
$$

The amount of spreading will depend on the spectrum of the irregularities. Equations (2) and (10) represent the conservation of momentum and energy in the wave scattering process.

It may be of interest to estimate the amount of frequency spreading due to electron plasma waves at the plasmapause where coherent aspect-sensitive backscattering are also observed [Carpenter et al., 2002; Fung et al., 2003]. Assuming a $200 \mathrm{kHz}$ transmitted wave, the backscatter condition above then implies the presence of irregularities with a cross-field scale $\lambda_{\mathrm{ir}} \sim 0.8 \mathrm{~km}$. From the dispersion relations of electron plasma waves, either Langmuir waves or upper-hybrid waves, we have $f_{\mathrm{ir}}{ }^{2}=\mathrm{f}_{\mathrm{p}}{ }^{2}\left[1+(3 / 2)\left(\lambda_{\mathrm{D}} / \lambda_{\mathrm{ir}}\right)^{2}\right]$ or $f_{\mathrm{ir}}{ }^{2}=$ $\mathrm{f}_{\mathrm{p}}^{2}+\mathrm{f}_{\mathrm{g}}{ }^{2}$, where $\lambda_{\mathrm{D}}=7.43 \mathrm{Te}^{1 / 2} \mathrm{~N}_{\mathrm{e}}^{-1 / 2}$ is the electron Debye length (in meter) with $\mathrm{T}_{\mathrm{e}}(\mathrm{eV})$ and $\mathrm{Ne}_{\mathrm{e}}\left(\mathrm{cm}^{-3}\right)$ being the electron temperature and electron density, respectively. Thus for a $\mathrm{T}_{e} \sim 1 \mathrm{eV}$ and a $\mathrm{N}_{\mathrm{e}} \sim 100 \mathrm{~cm}^{-3}$ appropriate for the plasmaspause region, we have $\left(\lambda_{\mathrm{D}} / \lambda_{\mathrm{ir}}\right)^{2}$ $\ll<1$ and $f_{\text {ir }}>f_{p} \sim 90 \mathrm{kHz}$, which implies that the scattered waves from the plasmapause can be changed by $\sim 50 \%$ of the transmitted frequencies. Given the prevalence of upperhybrid waves in the plasmapause region [Carpenter et al., 2002], we would expect to observe range spreading as well as frequency spreading in plasmapause echoes.

The Radio Plasma Imager (RPI) on IMAGE performed the first successful LR magnetospheric sounding [Reinisch et al., 200 lb, Fung et al., 2002]. The plasmagram in 
Figure 12 shows a collection of echoes resulting from direct sounding by RPI near the equatorial plasmapause. The vertical bright lines are gyroharmonic resonances from which the local electron gyrofrequency can be determined, $f_{\mathrm{g}}=16.34 \mathrm{kHz}$. Direct sounding of both the plasmapause and the outer plasmasphere resulted in spread echoes, indicating the presence of small-scale irregularities $\left(\lambda_{\mathrm{ir}} \sim 0.25-2 \mathrm{~km}\right)$ in these regions [Carpenter et al., 2002; Fung et al., 2003]. The discrete echo trace is due to signals guided along the geomagnetic field line and reflected from the high-latitude topside ionosphere. The similar amplitudes of the guided (discrete) and direct (spread) signals indicate that the guided signals have suffered very little path loss even though they have traveled much greater distances.

Figure 13 depicts the signal guiding mechanism in which total internal reflections trap and help guide radio signals along the geomagnetic field in a region of enhanced index of refraction, much like a waveguide or optical fiber. Field-aligned irregularities (FAI) are especially efficient in producing guided echoes and have been observed in the ionosphere. [James, 1989; Hanuise, 1983]. Observations of guided echoes throughout the magnetopshere imply that FAI are widely present [Carpenter et al., 2002; Fung et al., 2003].

\subsection{DETERMINATION OF MAGNETOSPHERIC PLASMA PARAMETERS}

Magnetospheric density and magnetic field strength can be determined by analyzing active sounding observations. We illustrate this by giving a few examples below.

\subsubsection{LOCAL DENSITY AND MAGNETIC FIELD STRENGTH}

Figure 14 shows observations of direct and guided echoes observed near the plasmapause $(\mathrm{L}=3.8)$. The inset shows the IMAGE orbital position at the time of observation. The direct echoes were reflected from inside the plasmasphere along the direction perpendicular to the geomagnetic field lines. The guided echoes, on the other hand, propagated along the $\mathrm{L}=3.8$ field line toward the high-latitude region and are reflected at 
the $f_{\mathrm{R}}$-cutoff altitudes. It is important to note the nearly vertical "up-side-down hook" feature of the guided echo trace. This feature indicates that the local $f_{\mathrm{R}}$-cutoff of the observation/transmission point was near $248 \mathrm{kHz}$, so waves at just above that frequency transmitted along the magnetic field propagate more slowly than waves at successively higher frequencies, leading to much longer virtual ranges (delay times) although the actual path is shorter.

Based on the nominal local $f_{\mathrm{g}}=22.2 \mathrm{kHz}$ determined from theTsygenanko-96 model magnetic field, the lines at $45,66.6$ and $110.9 \mathrm{kHz}$ are consistent with being the $2^{\text {nd }}, 3^{\text {rd }}$, and $5^{\text {th }}$ gyroharmonic resonances, which then yield an observed $f_{\mathrm{g}}=22.25 \mathrm{kHz}$. The $4^{\text {th }}$ harmonic was not detected because the programmed receiver frequencies $(300 \mathrm{~Hz}$ bandwidth), each separated by a $4 \%$-logarithmic frequency step, may not necessarily coincide with the harmonic frequencies. Using the $f_{R}$ and $f_{g}$ values, we can determine the electron plasma frequency to obtain $f_{\mathrm{P}}=236.6 \mathrm{kHz}$, consistent with the rather weak resonance observed at $233.6 \mathrm{kHz}$. The local plasma frequency thus determined corresponds to an electron density $\mathrm{N}_{\mathrm{e}}=700 \mathrm{~cm}^{-3}$.

\subsubsection{POLAR CAP DENSITY}

During IMAGE apogee passages over the northern polar region, polar cap echo traces have been observed to last up to three hours [Fung et al., 2002; 2003; Nsumei et $a l ., 2003]$. In this high latitude region, the geomagnetic field lines are nearly radial, so that direct echoes from the polar cap and field-aligned guided echoes are not easily distinguishable. Inversion of polar cap traces (either from direct or guided echoes) will yield the nearly radial density profiles of the polar cap. Figure 15A taken from Nsumei et al. [2003] shows the radial electron density profiles of three successive soundings of the polar cap at 8 minutes apart. The three different starting high radial distances indicate the changing positions of the IMAGE spacecraft, reaching lower densities at the higher altitudes. The high frequency pulses at the same frequency apparently reached the same limiting altitude in the polar cap. 
Combining successive observations taken over an interval, such as shown in Figure 15A, it is possible to construct two-dimensional images of polar cap density in the IMAGE orbit plane, as shown in Figure 15B for two different geomagnetic $\left(\mathrm{K}_{\mathrm{p}}\right)$ conditions. Figure 15B shows clearly the higher electron density content in the polar cap during geomagnetic active periods [Nsumei et al.,2003].

\subsubsection{FIELD-ALIGNED DENSITY PROFILES AND STORM-TIME DYNAMICS}

It has long been recognized that the electron density distribution along the geomagnetic field line is an important parameter for understanding magnetospheric dynamics. Its true measurement has not been possible until magnetospheric radio sounding became successful [Reinisch et al., 2001a]. As described in Reinisch et al., [2001a] and also in Fung et al., [2003], guided or ducted echoes observed in the plasmasphere and plasmapause regions provide the only means by which field-aligned electron density distributions, like the polar cap case in Figure 15A, can be measured instantaneously. When guided echoes are observed to reflect in conjugate hemispheres, they sometimes form the epsilon signature [Fung et al., 2003], yielding the field-aligned density distribution between the northern and southern hemispheres. Figure 16A shows two fieldaligned electron density profiles before and during a geomagnetic storm. The "quiet day model" was developed as a fit to derived field-aligned densities from a series of RPI plasmagrams, with ducted echoes, during one pass through the plasmasphere on the previous quiet day. The "measured" values are derived from one plasmagram of fieldaligned echoes during the storm. Figure $6 \mathrm{~A}$ clearly shows the evacuation of plasma between $\pm 40^{\circ}$ magnetic latitudes at $\mathrm{L}=2.7$ during the storm.

During the course of a geomagnetic storm lasting 2-3 days, the 14.5-hr IMAGE orbit allows RPI to perform many soundings through the plasmasphere at different $\mathrm{L}$ values and to obtain the corresponding electron density distributions along the different field lines, revealing the associated plasmaspheric dynamics. Figure 16B shows the dramatic density decreases that occurred throughout the outer plasmasphere during the geomagnetic storm of March 31-April 2, 2001 [Reinisch et al., 2003]. The upper panel in 
the figure shows the development of the storm as provided by the $D_{s t}$ index throughout the pre-storm to post-storm interval. The lower panel shows the filling factor of different flux tubes (L) (normalized to their pre-storm densities) as measured by their corresponding guided echo traces, as a function of storm phases. The figure clearly shows the depletion or shrinkage of the entire outer plasmasphere during the storm, with the formation of a new storm-time plasmapause near $L_{p p-s t o r m ~}=2.5$. Below this $L$ value, the plasmasphere is largely unaffected, indicating the limit to the magnetospheric electric field penetration. The full plasmasphere is recovered at about 2.5 days after the main phase of the storm.

\section{CONCLUSIONS}

Within the last 5 years significant progress has been made in both understanding the location and importance of natural emissions in the inner magnetosphere and in using active EM waves as a method for remote sensing inner magnetospheric dynamics and structure. In this brief review several key advances have been discussed which include: 1. The importance of lightning generated whistler mode waves in the plasmasphere has emerged as an important factor in maintaining the slot region in the electron radiation belts and becoming a component of plasmaspheric hiss.

2. A more complex picture in the source location of non-thermal continuum radiation has emerged than previously thought. In addition to the normal trapped and escaping continuum radiation generated in the pre-noon section, continuum radiation at kilometric wavelengths is generated in plasmaspheric notches that corotate with the Earth, and continuum enhancement is observed in the pre-dawn sector.

3. The AKR source region moves up auroral field lines and shifts toward midnight with increasing dipole tilt angle (summer) from a more low altitude and dusk location during the winter season.

4. From direct and ducted magnetospheric sounder waves, the density structure and evolution of the plasmasphere and polar cap have been determined providing the 
observations needed to understand the processes of plasmaspheric filling and the variability of polar cap outflows.

Acknowledgments. The authors will like to gratefully acknowledge discussions with W. W. L. Taylor and for allowing us to consult his comprehensive list of VLF ground transmitters. The National Aeronautics and Space Administration supported this research under proposal SECGIP03-0085.

\section{REFERENCES}

Able, B., and R. M. Thorne, Electron scattering loss in Earth's inner magnetosphere: 2. Sensitivity to model parameters, J. Geophys. Res., 103, 2397-2407. 1998.

André, R., F. Lefeuvre, F. Simonet, and U. S. Inan, A first approach to model the lowfrequency wave activity in the plasmasphere, Annales Geophys., 20, 981-996, 2002.

Appleton, E. V. and M. A. F. Barnett, On some direct evidence for downward atmospheric reflection of electric rays, Proc. R. Soc. Lond., 109A, 621-641, 1925.

Benson, R.F., Alouette 2 observations supporting the oblique echo model for the plasma frequency resonance, J. Geophys. Res., 76, 1083-1087, 1971.

Benson, R. F., Stimulated plasma waves in the ionosphere, Radio Sci., 12, 861-878, 1977.

Benson, R. F., Ionospheric investigations using digital Alouette/ISIS topside ionograms, in 1996 Ionospheric Effects Symposium, edited by J. M. Goodman, pp. 202-209, Alexandria, Virginia, 1996.

Benson, R.F., V. A. Osherovich, J. Fainberg, B. W. Reinisch, Classification of IMAGE/RPI-stimulated plasma resonances for the accurate determination of magnetospheric electron-density and magnetic-field values, J. Geophys. Res., 108(A5), 1207, doi:10.1029/2002JA009589, 2003.

Benson, R.F., J. Fainberg, R.A. Hess, V.A. Osherovich, and R.G. Stone, Comment on "Observation of long-duration gyroharmonic resonances: A refutation of the shortduration explanation for interpreting the anomalous URAP sounder spectra observed in the Io torus" by P. Canu, Radio Sci., 36, 1649-1652, 2001. 
Benson, R. F., J. L. Green, S. F. Fung, B. W. Reinisch,W. Calvert, D. M. Haines, J.-L.

Bougeret, R. Manning, D. L. Carpenter, D. L. Gallagher, P. H. Reiff, and W. W. L.

Taylor, Magnetospheric radio sounding on the IMAGE Mission, The Radio Science

Bulletin, 285, Union Radio-Scientifique Internationale (URSI), 9-20, 1998.

Born, Max and Emil Wolf, Principles of Optics, Cambridge University Press, Cambridge, UK, 1999.

Bortnik, J., U. S. Inan, and T. F. Bell, Energy distribution and lifetime of magnetospherically reflecting whistlers in the plasmasphere, J. Geophys. Res., 108(A5), 1199, doi:10.1029/2002JA009316, 2003.

Bowles, K. L., Observations of vertical incidence scatter from the ionosphere at 41

$\mathrm{Mc} / \mathrm{sec}$, Phys. Rev. Lett., 1:454, 1958.

Breit, G. and M. A. Tuve, A test for the existence of the conducting layer, Phys. Rev., 28, 554-575, 1926.

Budden, K. G., The theory of radio windows in the ionosphere and magnetosphere, $J$. Atoms. Terr. Phys., 42, 287-298, 1980.

Burch, J. L. ed., The IMAGE Mission, Reprinted from Space Science Review, 91, Nos. 1$2,2000$.

Calvert, W., The detectability of ducted echoes in the magnetosphere, J. Geophys. Res., $86,1609-1612,1981$.

Calvert, W., R. F. Benson, D. L. Carpenter, S. F. Fung, D. L. Gallagher, J. L. Green, D. M. Haines, P. H. Reiff, B. W. Reinisch, M. F. Smith, and W. W. L. Taylor, The feasibility of radio sounding in the magnetosphere, Radio Sci., 30, 1577-1595, Sep.Oct. 1995.

Calvert, W., R. F. Benson, D. L. Carpenter, S. F. Fung, D. L. Gallagher, J. L. Green, D. M. Haines, P. H. Reiff, B. W. Reinisch, M. F. Smith, and W. W. L. Taylor, Reply to Comment on "The feasibility of radio sounding in the magnetosphere", Radio Sci., 32 (1), 281-284, Jan.-Feb. 1997.

Canu, P., Observation of long-duration gyroharmonic resonances: A refutation of the short-duration explanation for interpreting the anomalous URAP sounder spectra observed in the Io torus, Radio Sci., 36, 171-181, 2001a:

Canu, P., Reply, Radio Sci., 36, 1645-1647, 2001b. 
Canu, P., et al., Identification of natural plasma emissions observed close to the plasmapause by the Cluster-Whisper relaxation sounder, Ann. Geophysicae, 19, 1697$1701,2001$.

Carpenter, D. L., R. R. Anderson, W. Cálvert, and M. B. Moldwin, CRRES observations of density cavities inside the plasmasphere, J. Geophys. Res., 105, 23323-23338, 2000.

Carpenter, D. L., M. Spasojevic, T. F. Bell, U. S. Inan, B. W. Reinisch, I. A. Galkin, R. F. Benson, J. L. Green, S. F. Fung, and S. A. Boardsen, Small-scale field-aligned plasmaspheric density structures inferred from RPI on IMAGE, J. Geophys. Res., 107(A9), 1258, doi:10.1029/2001JA009199, 2002.

Davies, K., Ionospheric Radio, Peter Peregrinus Ltd., London, U.K., 1990.

Décréau, P. M. E., et al., Observation of continuum radiations from the CLUSTER fleet: first results from direction finding, Annales Geophysicae, in press, 2004.

de Feraudy, J. Hanasz, R. Schreiber, G. Parks, M. Brittnacher, S. Perraut, J. A. Sauvaud, F. Lefeuvre, and M. M. Mogilevsky, AKR bursts and substorm field line excitation, Phys. Chem, Earth, 26, 151-159, 2001.

Delory, G. T., R. E. Ergun, C. W. Carlson, L. Muschietti, C. C. Chaston, W. Peria, J. P. McFadden, and R. Strangeway, FAST observations of electron distributions within AKR source regions, Geophys. Res. Lett. 25, 2069-2072, 1998.

Dougherty, J. P., and D. T. Farley, A theory of incoherent scattering of radio waves by a plasma, Proc. Roy. Soc. (London), A259, 79, 1960.

Ergun, R. E., C. W. Carlson, J. P. McFadden, F. S. Mozer, G. T. Delory , W. Peria , C. C. Chaston, M. Temerin, R. Elphic, R. Strangeway, R. Pfaff, C. A. Cattell, D. Klumpar, E. Shelly, W. Peterson, E. Moebius, L. Kistler, FAST satellite wave observations in the AKR source region, Geophys. Res. Lett., 25, 2061-2065, 1998.

Ergun, R. E., C. W. Carlson, J. P. McFadden, G. T. Delory, R. J. Strangeway, and P. L. Pritchett, Electron-cyclotron maser driven by charged-particle acceleration from magnetic field-aligned electric fields, Astrophys. J., 538, 456-466, 2000.

Etcheto, J. and J.J. Bloch, Plasma density measurements from the GEOS-1 relaxation sounder, Space Science Reviews, 22, 597-610, 1978.

Etcheto, J., G. Belmont, P. Canu, and J.G. Trotignon, Active sounder experiments on GEOS and ISEE, in Active Experiments in Space, Proceedings of an International 
Symposium held at Alpbach, Austria 24-28 May 1983, 39-46, European Space Agency, Noordwijk, Netherlands, 1983.

Fejer, B. G. and M. C. Kelley, Ionospheric irregularities, Rev. Geophys. Space Phys., 18, 401-454, 1980.

Franklin, C. A. and M. A. Maclean, The design of swept-frequency topside sounders. Proc. IEEE, 57, 897-929, 1969.

Fung, S. F. and A. F. Vinas, Excitation of high frequency electromagnetic waves by energetic electrons with an effective loss cone distribution, J. Geophys. Res., 99, 86718686, 1994.

Fung, S. F. and K. Papadopoulos, The emission of narrow-band Jovian kilometric radiation, Journal of Geophysical Research, 92, 8579-8593, 1987.

Fung, S. F., R. F. Benson, D. L. Carpenter, B. W. Reinisch, and D. L. Gallagher, Investigations of irregularities in remote plasma regions by radio sounding: applications of the Radio Plasma Imager on IMAGE, Space Sci. Rev., 91, 391-419, 2000.

Fung, S. F., R. F. Benson, J. L. Green, B. W. Reinisch, D. M.Haines, I. A. Galkin, J.-L. Bougeret, R. Manning, P. H. Reiff, D. L. Gallagher, D. L. Carpenter, and W. W. L. Taylor, Observations of Magnetospheric Plasmas by the Radio Plasma Imager on the IMAGE Mission, Advances in Space Research, 30, 2259-2266, 2002.

Fung, S. F., R. F. Benson, D. L. Carpenter, J. L. Green, V. Jayanti, I. A. Galkin, and B. W. Reinisch, Guided Echoes in the Magnetosphere: Observations by Radio Plasma Imager on IMAGE, Geophys. Res. Lett, 3O(11), 1589, doi:10.1029/2002GL016531, 2003.

Gallagher, D. L. and D. A. Gurnett, Auroral kilometric radiation: Time-averaged source location, J. Geophys. Res., 84, 6501-6509, 1979.

Gough, M. P., Nonthermal continuum emissions associated with electron injections: Remote plasmapause sounding, Planet. Space Sci., 30, 657, 1982.

Green, J. L., R. F. Benson, W. Calvert, S. F. Fung, P. H. Reiff, B. W. Reinisch, and W. W. L. Taylor, A Study of Radio Plasma Imaging for the proposed IMI mission, NSSDC Technical Publication, February 1993.

Green, J. L. and S. A. Boardsen, Confinement of non-thermal continuum radiation to low latitudes, J. Geophys. Res., 104, 10307-10316, 1999. 
Green, J. L., B. R. Sandel, S. F. Fung, D. L. Gallagher, and B. W. Reinisch, On the origin of kilometric continuum, J. Geophys. Res., 107(A7), 10.1029/2001JA000193, 2002.

Green, J. L., S. A. Boardsen, S. F. Fung, H. Matsumoto, K. Hashimoto, R. R. Anderson, B. R. Sandel, and B. W. Reinisch, Association of kilometric continuum radiation with plasmaspheric structures, J. Geophys. Res., A03203, doi:10.1029/2003JA010093, 2004a.

Green, J. L., S. A. Boardsen, L. Garcia, S. F. Fung, and B. W. Reinisch, Seasonal and solar cycle dynamics of the AKR source region, , J. Geophys. Res., 109, A05223, doi:10.1029/2003JA010311, 2004b.

Greenwald, R. A., Comment on "The feasibility of radio sounding in the magnetosphere" by W. Calvert et al., Radio Sci., 32, 277-280, 1997a.

Greenwald, R. A., Rebuttal to reply by W. Calvert et al., Radio Sci., 32, 877-879, $1997 \mathrm{~b}$.

Gurnett, D. A., The Earth as a radio source: Terrestrial kilometric radiation, J. Geophys. Res., 79, 4227-4238, 1974.

Gurnett, D. A., The Earth as a radio source: The nonthermal continuum, J. Geophys. Res., $80,2751-2763,1975$.

Gurnett, D. A. and R. A. Shaw, Electromagnetic radiation trapped in the magnetosphere above the plasma frequency, J. Geophys. Res., 78, 8136-8148, 1973.

Gurnett, D. A. and L. A. Frank, Continuum radiation associated with low-energy electrons in the outer radiation zone, J. Geophys. Res., 81, 3875- 3885, 1976.

Gurnett, D. A., W. Calvert, R. L. Huff, D. Jones, and M. Sugiura, The polarization of escaping terrestrial continuum radiation, J. Geophys. Res., 93, 12817-12825, 1988.

Hanasz, J., M. Y. Boudjada, R. Schreiber, Z. Krawczyk, M. Malycha, M. M. Mogilevsky, H. O. Rucker, and T. V. Romantsova, Dynamic spectra of the Stokes parameters for the dayside and nightside auroral kilometric radiation, Geophys. Res. Lett., 27, 1631-1634, 2000 .

Hanasz, J., H. de Feraudy, R. Schreiber, G. Parks, M. Brittnacher, M. M. Mogilevsky, T. V. Romantsova, Wideband bursts of auroral kilometric radiation and their association with UV auroral bulges, J. Geophys. Res., 106, 3859-3871, 2001. 
Hanasz, J., M. Panchenko, H. de Feraudy, R. Schreiber, and M. M. Mogilevsky,

Occurrence distributions of the auroral kilometric radiation ordinary and extraordinary wave modes, J. Geophys. Res., 108(A11), 1408, doi:10.1029/2003JA010093, 2003.

Hanuise, C., High-latitude ionospheric irregularities: a review of recent radar results, Radio Sci., 18, 1093-1121, 1983.

Hashimoto, K., W. Calvert, and H. Matsumoto, Kilometric continuum detected by Geotail, J. Geophys. Res., 104, 28645-28656, 1999.

Helliwell, R. A., VLF wave stimulation experiments in the magnetosphere from Siple Station, Antarctica, Rev. Geophys., 26, 551-578, 1988.

Hilgers, A., A. Roux, and R. Lundin, Characteristics of AKR sources; a statistical description, Geophys. Res. Lett., 18, 1493-1496, 1991.

Hunsucker, R. D., Radio Techniques for Probing the Terrestrial Ionosphere, Vol. 22, Phys. Chem. Space, Springer-Verlag, Berlin, 1992.

Huang, X. and B. W. Reinisch, Automatic calculation of electron density profiles from digital ionograms 2 . True height inversion of topside ionograms with the profile-fitting method, Radio Sci., 17,837-844, 1982.

James, H. G., ISIS 1 measurements of high-frequency backscatter inside the ionosphere, J. Geophys. Res., 94, 2617-2629, 1989

Jackson, J. E., Alouette-ISIS Program Summary, NSSDC Report 86-09, National Space Science Data Center, Greenbelt, Maryland, 1986.

Jackson, J. E., The reduction of topside ionograms to electron-density profiles, Proc. IEEE, 57, 960-976, 1969.

Jones, D., Source of terrestrial non-thermal continuum radiation, Nature, 260, 686-689, 1976.

Jones, D., W. Calvert, D. A. Gurnett, and R. L. Huff, Observed beaming of terrestrial myriametric radiation, Nature, 328, 931-394, 1987.

Kasaba, Y., H. Matsumoto, and K. Hashimoto, The angular distribution of auroral kilometric radiation observed by the GEOTAIL spacecraft, Geophys. Res. Lett., 20, 2483-2486, 1997.

Kasaba, Y., H. Matsumoto, K. Hashimoto, R. R. Anderson, J.-L. Bougeret, M. L. Kaiser, $\mathrm{X}$. Y. Wu, and I. Nagano, Remote sensing of the plasmapause during substorms: 
GEOTAL observation of nonthermal continuum enhancement, J. Geophys. Res., I03, 20389-20405, 1998.

Kelley, M. C., The Earth's Ionosphere, Academic Press, San Diego, CA, 425-434, 1989.

Kennel, C. F. and H. E. Petschek, Limit on stably trapped particle fluxes, J. Geophys. Res., 71, 1-28, 1966.

Kumamoto, A. and H. Oya, Asymmetry of occurrence frequency and intensity of AKR between summer polar region and winter polar region, Geophys. Res. Lett., 25, 23692372, 1998.

Kumamoto, A., T. Ono, M. lizima, and H. Oya, Seasonal and solar cycle variations of the vertical distribution of occurrence probability of auroral kilometric radiation sources and of upflowing ion events, J. Geophys. Res., 108(Al), doi:10:1029/2002JA009522, 2003.

Kurth, W. S., M. M. Baumback, and D. A. Gurnett, Direction-finding measurements of auroral kilometric radiation, J. Geophys. Res., 80, 2764-2770, 1975.

Kurth, W. S., J. D. Craven, L. A. Frank, and D. A. Gurnett, Intense electrostatic waves near the upper hybrid resonance frequency, J. Geophys. Res., 84, 4145, 1979.

Kurth, W. S., D. A. Gurnett, and R. R. Anderson, Escaping nonthermal continuum radiation, J. Geophys. Res., 86, 5519-5531, 1981.

Lee, L. C., J. R. Kan, and C. S. Wu, Generation of Auroral Kilometric Radiation and the structure of the auroral acceleration region, Planet. Space Sci., 28, 703-711, 1980.

LeSager, P., P. Canu, and N. Cornilleau-Wehrlin, Impact of the Ulysses velocity on the diagnosis of the electron density by the Unified Radio and Plasma Wave sounder in the outskirts of the Io torus, J. Geophys. Res., 103(AL1), 26667-26677, 1998.

Meredith, N. P., R. B. Horne, R. M. Thorne, D. Summers, M. C. Cain, and R. R. Anderson, Evidence for Chorus-driven electron acceleration to relativistic energies from a survey of geomagnetically-disturbed periods, this monograph, 2004.

Melrose, D. B., A theory for the nonthermal radio continua in the terrestrial and Jovian magnetospheres, J. Geophys. Res., 86, 30-36, 1981.

Menietti, J. D., H. K. Wong, W. S. Kurth, D. A. Gurnett, J. Grandroth, and J. B. Groene, Discrete, stimulated auroral kilometric radiation observed in the Galileo and DE-1 wideband data, J. Geophys. Res., 101, 10673, 1996. 
Menietti, J. D., A. M. Persoon, J. S. Pickett, D. A. Gurnett, Statistical study of auroral kilometric fine structure striations observed by Polar, J. Geophys. Res., 105, 18857$18866,2000$.

Menietti, J. D., R. R. Anderson, J. S. Pickett, D. A. Gurnett, and H. Matsumoto, Nearsource and remote observations of kilometric continuum radiation from multispacecraft observations, J. Geophys. Res., 108(A11), 1393, doi:10.1029/2003JA009826, 2003.

Morgan, D. D. and D. A. Gurnett, The source location and beaming of terrestrial continuum radiation, J. Geophys. Res., 96, 9595-9613, 1991.

Muldrew, D.B., Electron resonances observed with topside sounders, Radio Sci., 7, 779789, 1972.

Mutel, R. L., D. A. Gurnett, I. W. Christopher, J. S. Pickett, and M. Schlax, Locations of auroral kilometric radiation bursts inferred from multispacecraft wideband Cluster VLBI observations. 1: Description of technique and initial results, J. Geophys. Res., 108(A11), 1398, doi:10.1029/2003JA010011, 2003.

Mutel, R. L., D. A. Gurnett, and I. W. Christopher, Spatial and temporal properties of AKR burst emissions derived from Cluster WBD VLBI studies, Ann. Geophys., Accepted for publication, 2004.

Nagano, I., X.-Y. Wu, H. Takano, S. Yagitani, H. Maatsumoto, K. Hashimoto, and Y. Kasaba, Remote sensing the magnetosheat by the spin modulation of terrestrial continuum radiation, J. Geophys. Res., 108(A6), 1224, doi:10.1029/2002JA009691, 2003.

Nelms, G.L. and G.E.K. Lockwood, Early results from the topside sounder in the Alouette II satellite, in Space Research VII, edited by R.L. Smith-Rose, North-Holland Publishing Co., Amsterdam, 604-623, 1967.

Newell, P. T., Ching-I Meng, and K. M. Lyons, Suppression of discrete aurorae by sunlight, Nature, 381, 766-767, June 27, 1996.

Nsumei, P. A., X. Huang, B. W. Reinisch, P. Song, V. M. Vasyliunas, J. L. Green, S. F. Fung, R. F. Benson, and D. L. Gallagher, Electron density distribution over the northern polar region deduced from IMAGE/RPI sounding, J. Geophys. Res., 108(A2), 1078, doi:1.1029.2002JA/009616, 2003. 
Ondoh, T., Y. Nakamura, and T. Koseki, Feasibility of plasmapause sounding from a geostationary satellite, Space Sci. Instrum., 4, 57-71, 1978.

Osherovich, V.A., Physical nature of the diffuse plasma resonances in the ionosphere, $J$. Geophys. Res., 92, 316-320, 1987.

Osherovich, V.A., The physical nature of the upper subsidiary diffuse resonances, $J$. Geophys. Res., 94, 5530-5532, 1989.

Osherovich, V.A. and R.F. Benson, The lower subsidiary diffuse plasma resonances and the classification of radio emissions below the plasma frequency, J. Geophys. Res., 96, 19331-19341, 1991.

Oya, H., Sequence of diffuse plasma resonances observed on Alouette 2 ionograms, $J$. Geophys. Res., 75, 4279-4285, 1970.

Oya, H., A. Morioka, K. Kobayashi, M. Iizima, T. Ono, H. Miyaoka, T. Okada and T. Obara, Plasma wave observation and sounder experiments (PWS) using the Akebono (EXOS-D) satellite - Instrumentation and initial results including discovery of the high altitude equatorial plasma turbulence, J. Geomagn. Geoelectr., 42, 411-442, 1990.

Oya, H. and T. Ono, Stimulation of plasma waves in the magnetosphere using satellite JIKIKEN (EXOS-B). Part II: Plasma density across the plasmapause, J. Geomagn. Geoelectr., 39, 591-607, 1987.

Panchenko, M., Direction finding of AKR sources with three orthogonal antennas, Radio Sci., 28(6), 1099, doi:10.1029/2003RS002929, 2003.

Perraut, S., H. d. Feraudy, A. Roux, P. M. E. Kelley, J. Paris, and L. Matson, Density measurements in key regions of the Earth's magnetosphere: Cusp and auroral region, $J$. Geophys. Res., 95, 5997-6014, 1990.

Reinisch, B. W., D. M. Haines, K. Bibl, G. Cheney, I. A. Galkin , X. Huang, S. H. Myers, G. S. Sales, R. F. Benson, S. F. Fung, J. L. Green, W. W. L. Taylor, J.-L. Bougeret, R. Manning, N. Meyer-Vernet, M. Moncuquet, D. L. Carpenter, D. L. Gallagher, and P. Reiff, The Radio Plasma Imager investigation on the IMAGE spacecraft, Space Science Reviews, 91, 319-359, February, 2000.

Reinisch, B.W., X. Huang, P. Song, G. S. Sales, S. F. Fung, J. L. Green, D. L. Gallagher, and V. M. Vasyliunas, Plasma density distribution along the magnetospheric field: RPI observations from IMAGE, Geophys. Res. Lett., 28, 4521-4524, 2001 a. 
Reinisch, B. W., X. Huang, D. M. Haines, I. A. Galkin, J. L. Green, R. F. Benson, S. F. Fung, W. W. L. Taylor, P. H. Reiff, D. L. Gallagher, J.-L. Bougeret, R. Manning, D. L. Carpenter and S. A. Boardsen, First results from the Radio Plasma Imager on IMAGE, Geophys. Res. Lett., 28, 6, 1167-1170, $2001 \mathrm{~b}$.

Reinisch, B. W., X. Huang, P. Song, S. F. Fung, J. L. Green, V. M. Vasyliunas, D. L. Gallagher, and B. R. Sandel, Plasmaspheric Mass Loss and Refilling as a Result of a Magnetostorm, J. Geophys. Res., J. Geophys. Res., 109(A 1), A01202, doi:10.1029/2003JA009948, 2003.

Rodger, C. J., M. A. Cilverd, and R. J. McCormick, Significance of lightning-generated whistlers to inner radiation belt electron lifetimes, J. Geophys. Res., 108(A12), 1462, doi:10.1029/2003JA009906, 2003.

Santolik, O., M. Parrot, L. R. O. Storey, J. S. Pickett, and D. A. Gurnett, Propagation analysis of plasmaspheric hiss using Polar PWI measurements, Geophys. Res. Lett., 28, 1127-1130, 2001.

Shawhan, S. D., Magnetospheric plasma wave research 1975-1978, Rev. Geophys. \& Sp. Phys., 705-724, June 1979.

Stix, T. H., Waves in Plasmas, AIP Press, New York, 1992.

Storey, L. R. O., An investigation of whistling atmospherics, Phil. Trans. Roy. Soc., 246, 113-141, 1953.

Storey, L. R. O. and F. Lefeuvre, The analysis of 6-component measurements of a random electronmagnetic wave field in a magnetoplasma, 1 : The direct problem, Geophys. J. R. Astron. Soc., 56, 255-270, 1979.

Storey, L. R. O., F. Lefeuvre, M. Parrot, L. Cairo, and R. R. Anderson, Initial survey of the wave distribution functions for plasmaspheric hiss observed by ISEE 1, J. Geophys. Res., 96, 19469-19489, 1991.

Thorne, R. M., S. R. Church, and D. J. Gorney, On the origin of Plasmaspheric hiss: The importance of wave propagation and the plasmapause, J. Geophys. Res., 84, 5241-5247. 1979.

Trotignon, J. G., et al., How to determine the thermal electron density and the magnetic field strength from the Cluster/Whisper observations around the earth, Ann.

Geophysicae, 19, 1711-1720, 2001. 
Trotignon, J. G., J. Etcheto, and J. P. Thouvenin, Automatic determination of the electron density measured by the relaxation sounder on board ISEE 1, J. Geophys. Res., 91 (A4), 4302-4320, 1986.

Warnock, J.M., Sideband structure observed by topside sounders, Proc. IEEE, 57, 1135 $1139,1969$.

Warren, E. S. and E. L. Hagg, Observation of electrostatic resonances of the ionospheric plasma, Nature, 220, 466-468, 1968.

$\mathrm{Wu}, \mathrm{C}$. S. and L. C. Lee, A theory of the terrestrial kilometric radiation, Astrophys. J., 230, 621-626, 1979. 


\section{Figure Captions}

Figure 1. Trapped and escaping waves modes in a plasma in which the $f_{p}>f_{g}$ illustrating the upper and lower frequency cutoffs and resonances.

Figure 2. A summary of the four whistler mode waves in the inner magnetosphere as a function of their frequency range that are reviewed in this paper.

Figure 3. Average plasmaspheric magnetic field spectral density showing frequency and radial distance distribution of whistler mode waves in the plasmasphere [after André et al., 2002].

Figure 4 Schematic of the longitudinal distribution of the whistler mode waves in the plasmasphere.

Figure 5. The observed source locations of the escaping [after Décréau, et al., 2004], trapped [after Gurnett and Frank, 1976], kilometric [after Hashimoto et al., 1999] and continuum enhancement [after Kasaba, et al., 1998] emissions.

Figure 6. The observed emission cone of the trapped continuum radiation from four years of Hawkeye plasma wave observations at $31.1 \mathrm{kHz}$ overlaid with ray tracing calculations at that same frequency [after Green et al., 1999]. The ray tracing calculations show the narrow range in wave normal angles about the magnetic equator in which the emission is reflected between the magnetopause and the plasmapause.

Figure 7. The $\mathrm{KC}$ wave observations from Geotail/PWI (panel A) map to a plasmaspheric notch structure as observed by IMAGE/EUV (panel B) where the resulting emission cone pattern (panel $\mathrm{C}$ ) is modeled with ray tracing calculations [after Green et al., 2002 and 2004a]. 
Figure 8. The average spectrum of AKR from two years of data from IMAGE/RPI with respect to dipole tilt (panel $\mathrm{A}$ ) clearly shows the dramatic frequency shift from high to low frequencies with increasing dipole tilt angle. Panel B illustrates the shift in the auroral zone density cavities corresponding to the observations in panel A [after Green et al., 2004b].

Figure 9. Detailed polarization measurement of AKR showing the L-O and R-X polarization components [after Hanasz, et al., 2000].

Figure 10: AKR source region measurements from the Cluster/WBD instrument using all four spacecraft as a long baseline interferometer array. Panel A shows AKR burst locations during a southern hemisphere (winter) pass while panel B shows the shift in the AKR source measurements to earlier local times during a northern hemisphere (winter) pass [after Mutel, et al., 2004].

Figure 11: Different types of possible echoes resulting from direct long-range sounding. Guided echoes are produced by signals trapped by total internal reflection along fieldaligned plasma irregularities. Direct (specular-reflected) echoes are produced by signals reflected by a wave cutoff, e.g at $f=f_{\mathrm{p}}$.

Figure 12: Echoes resulting from direct radio sounding from outside the plasmapause $(\mathrm{L}$ $=5.0,26^{\circ} \mathrm{MLAT}, 16.4 \mathrm{MLT}$ ), showing plasma resonances, scattered (spread), and guided (discrete) echoes [after Fung et al., 2003].

Figure 13: A sketch of field-aligned guided echoes trapped by total internal reflections. Field-aligned plasma irregularities create regions of enhanced refractive index $n$ along geomagnetic field lines, causing radio signals to be guided by total internal reflections.

Figure 14: Observations of local resonances and local cutoffs of guided and direct echo traces near the plasmapause allow the determination of the local plasma parameters $f_{\mathrm{p}}$ and $f_{\mathrm{g}}$. 
Figure 15: (A) Polar cap radial density profiles obtained from successive RPI soundings; (B) 2-dimensional images of the polar cap structure during geomagnetic active and quiet periods [after Nsumei et al., 2003].

Figure 16: (A) Field-aligned electron density distributions at $L=2.8$ before (the "quiet day model" is obtain from a fit of previous observations) and during a geomagnetic storm on April 1, 2001; and (B) the depletion of the entire outer plasmasphere $(\mathrm{L}>2.5)$ and the establishment of a new plasmapauses during and after the geomagnetic storm [after Reinisch et al., 2003]. 


\section{Frequency}

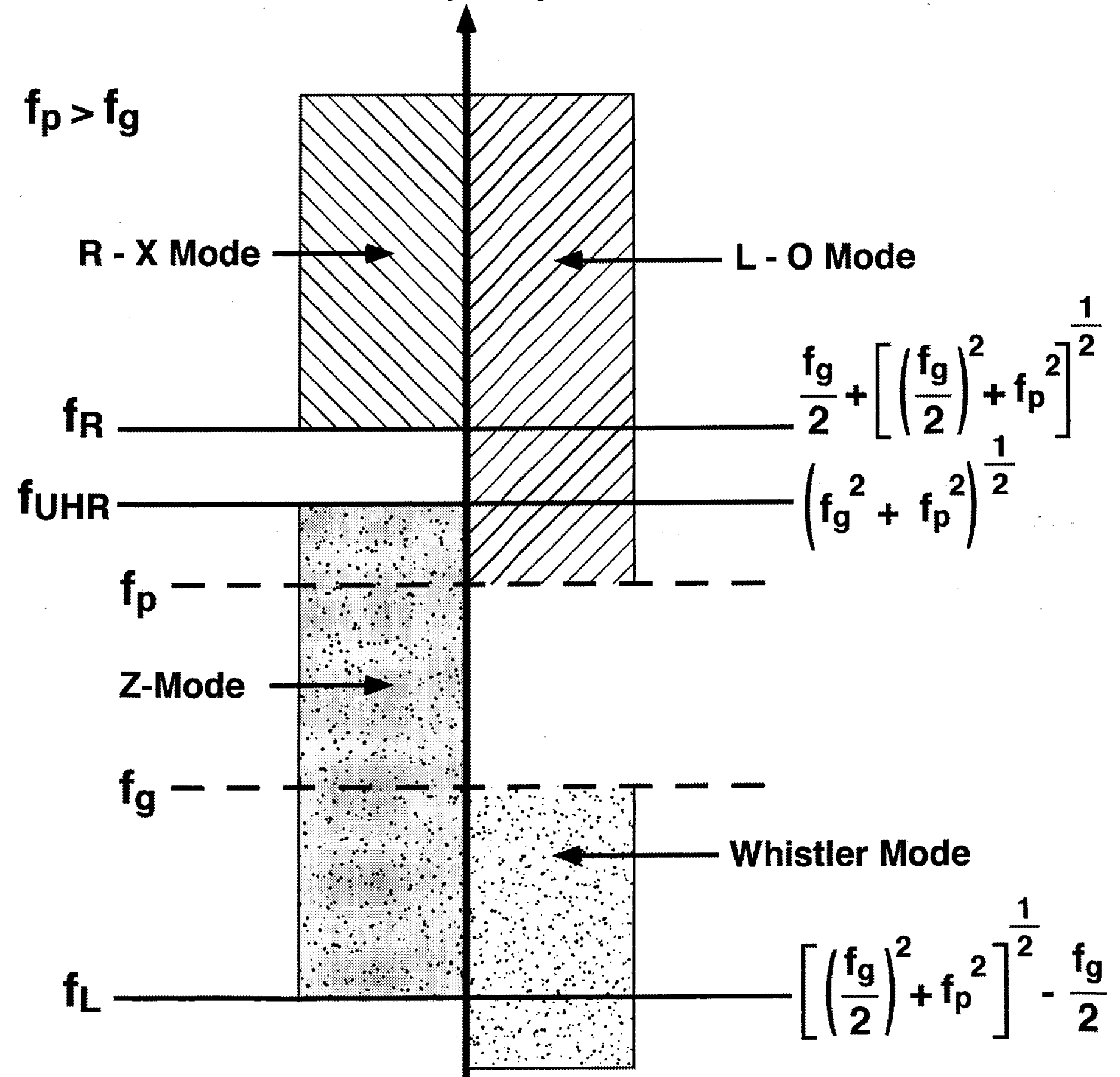

\section{Figure 1}




\section{Whistler Mode Waves}

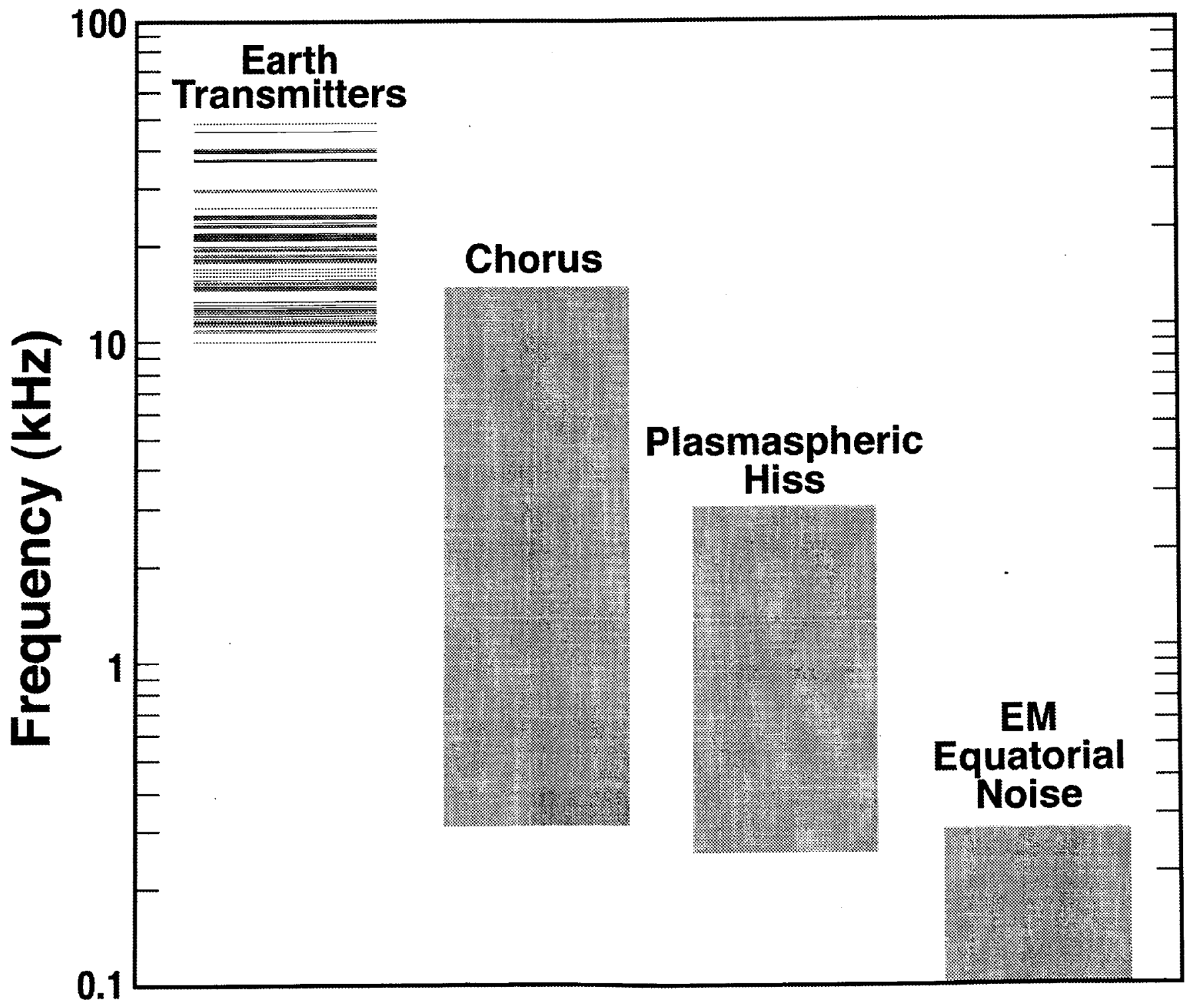

Figure 2 


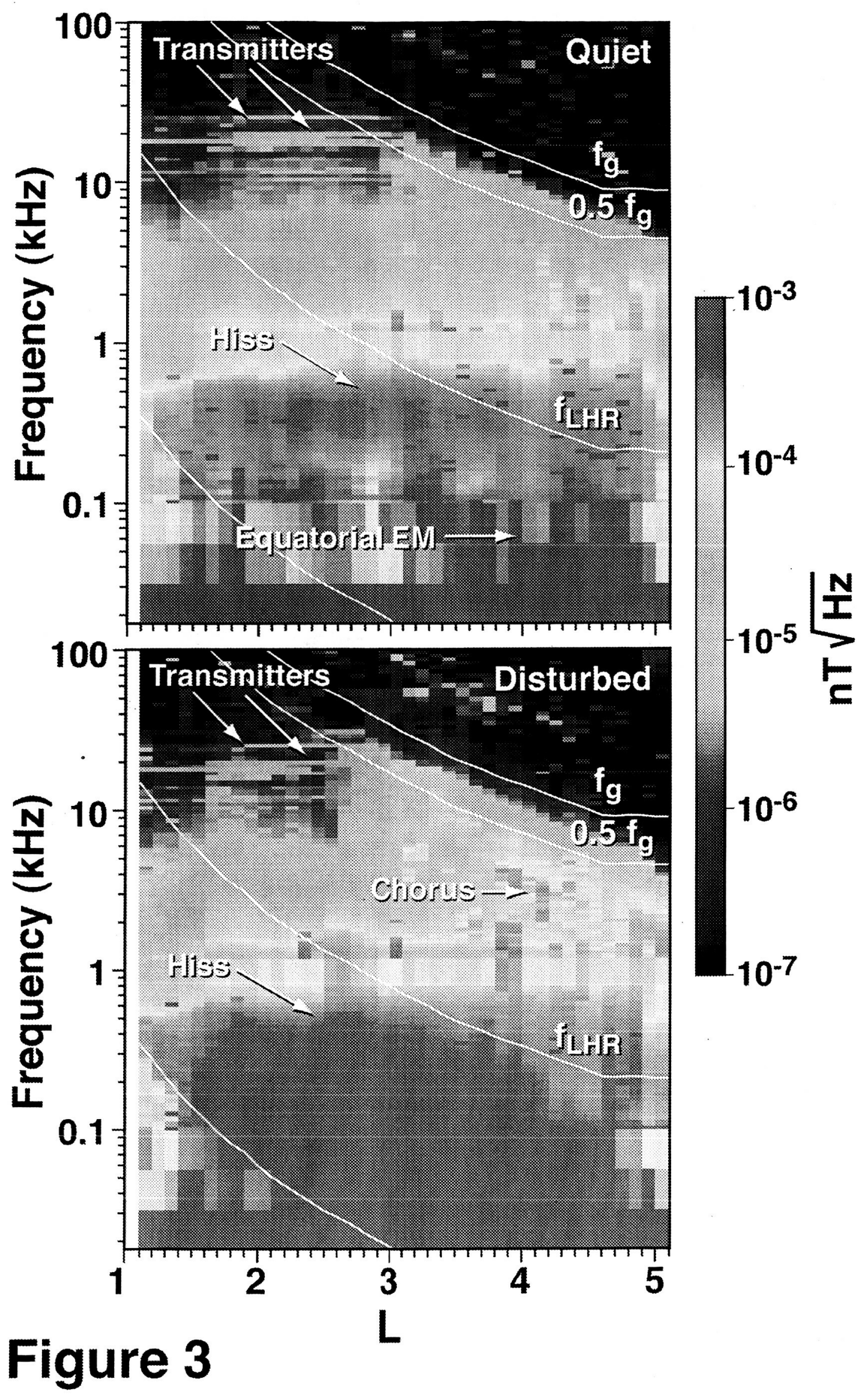




\section{Whistler Mode Waves in the Plasmasphere}

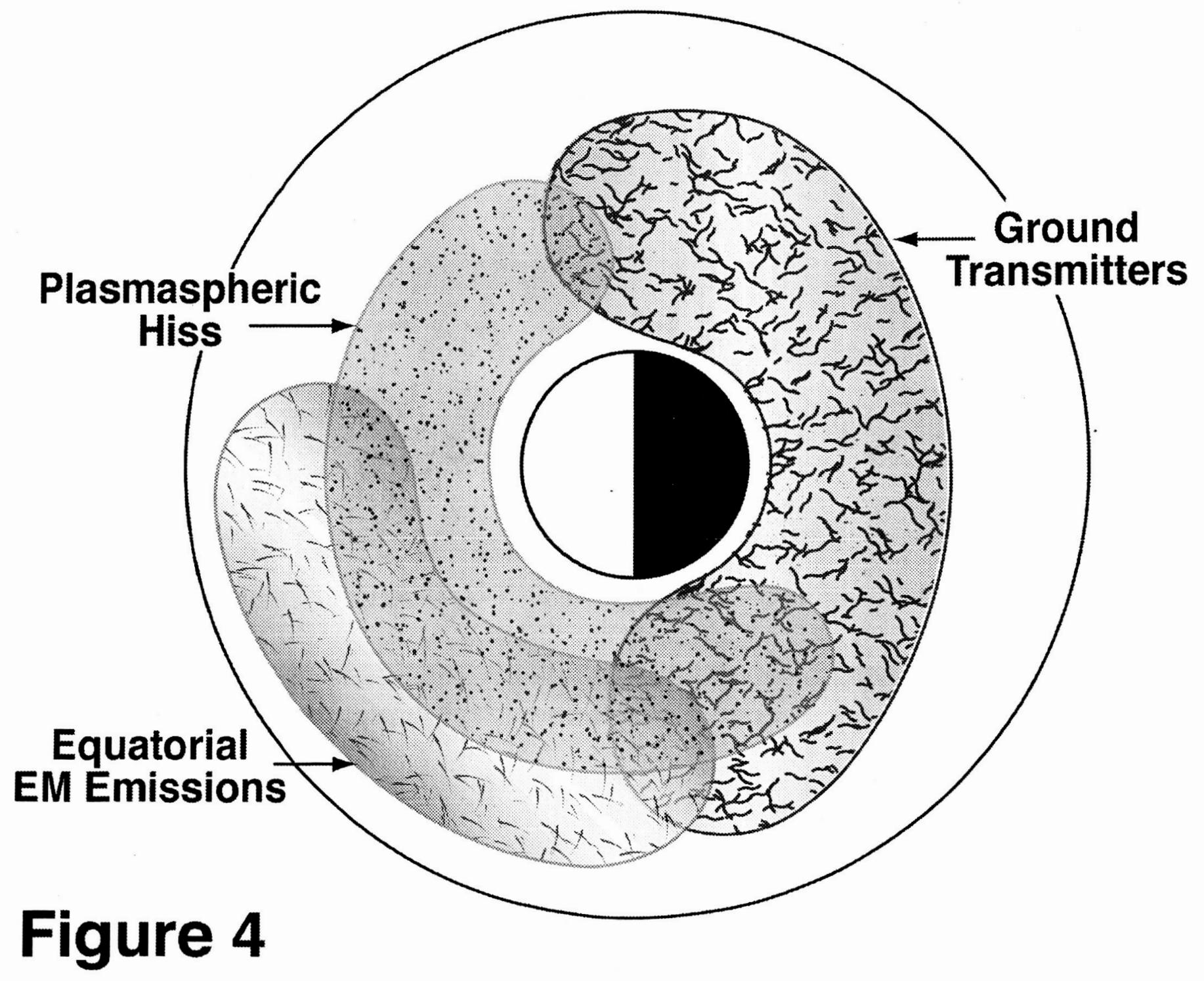




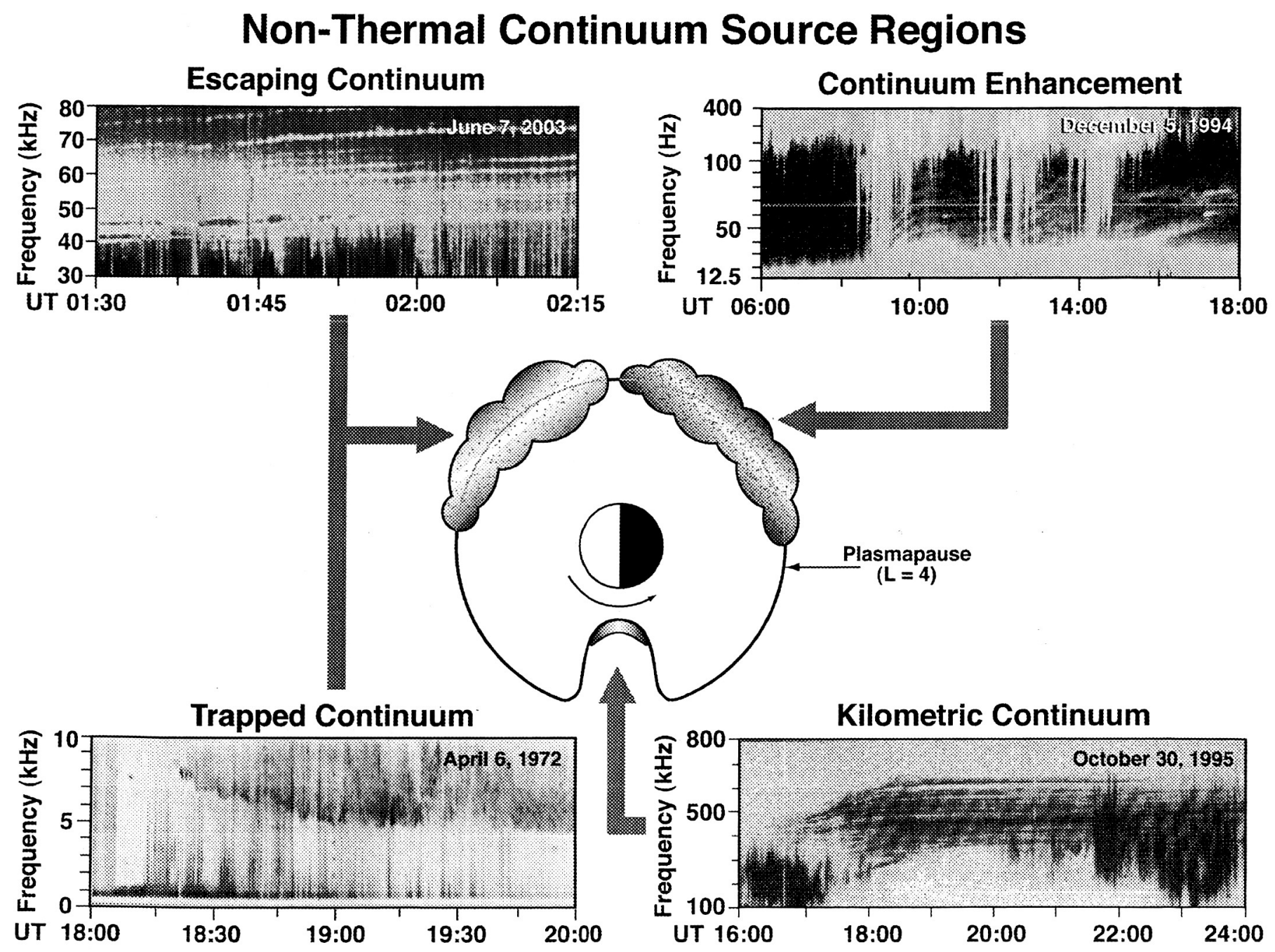

Figure 5 


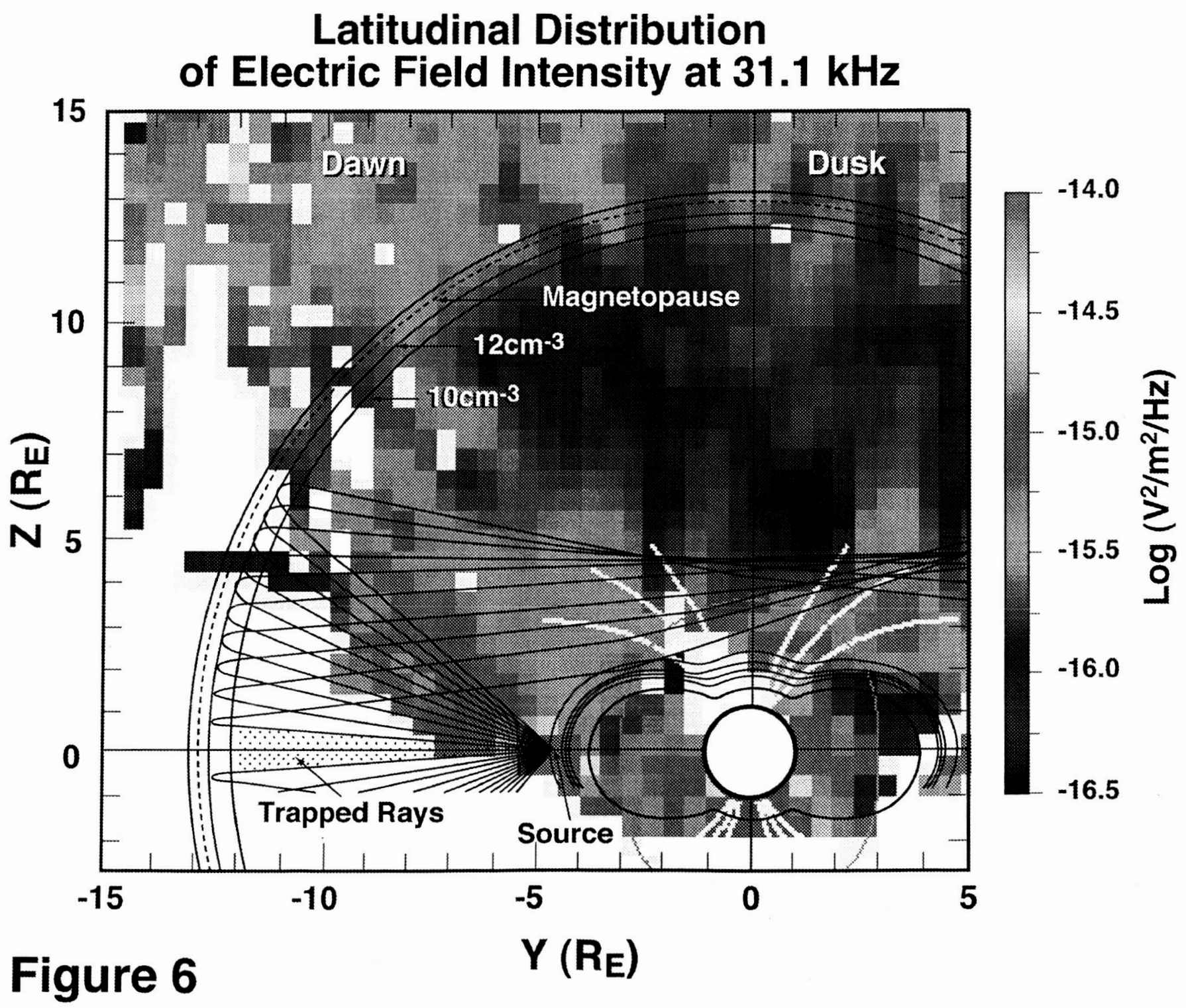




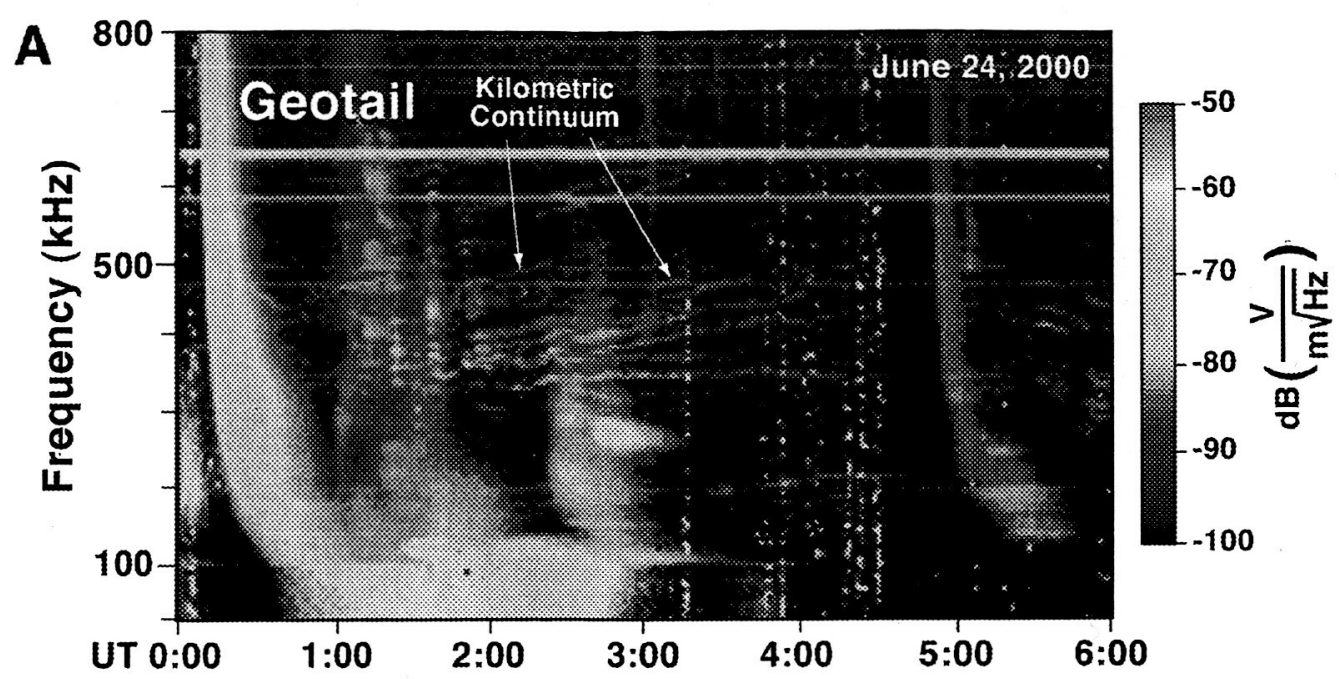

B

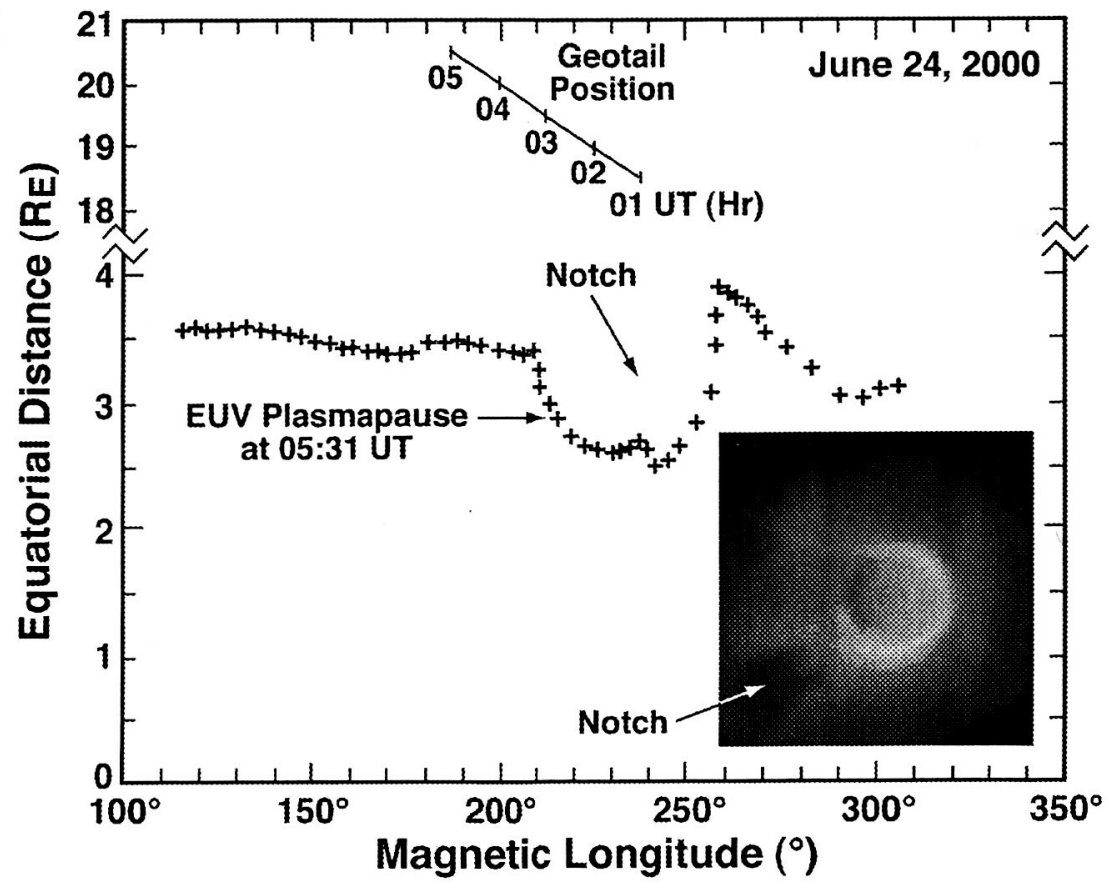

C

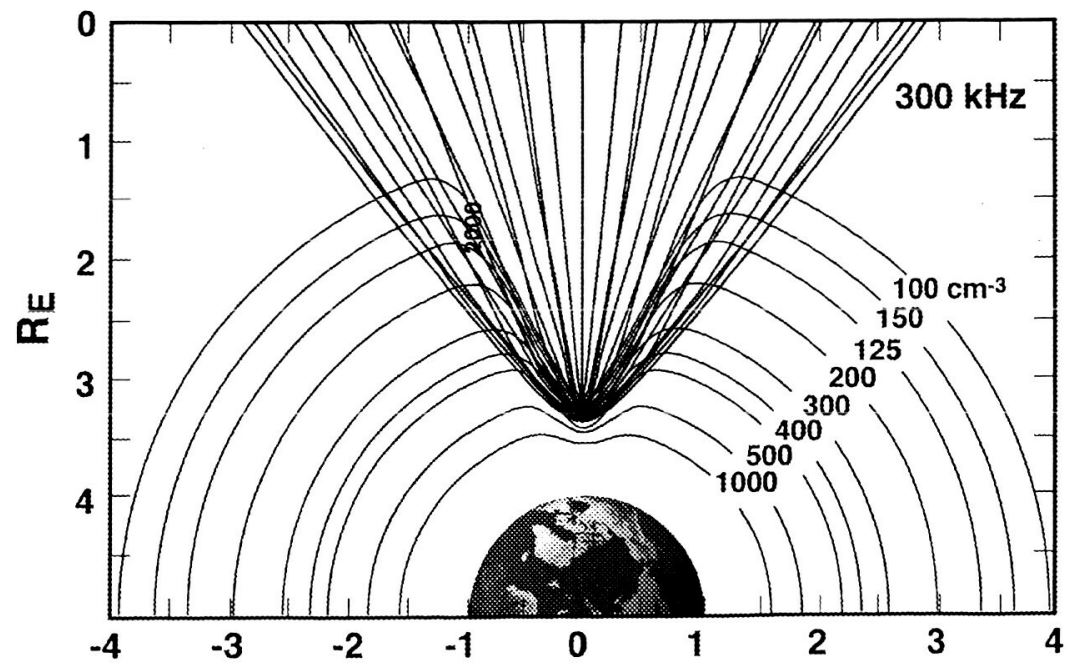

Figure 7

$R_{E}$ 


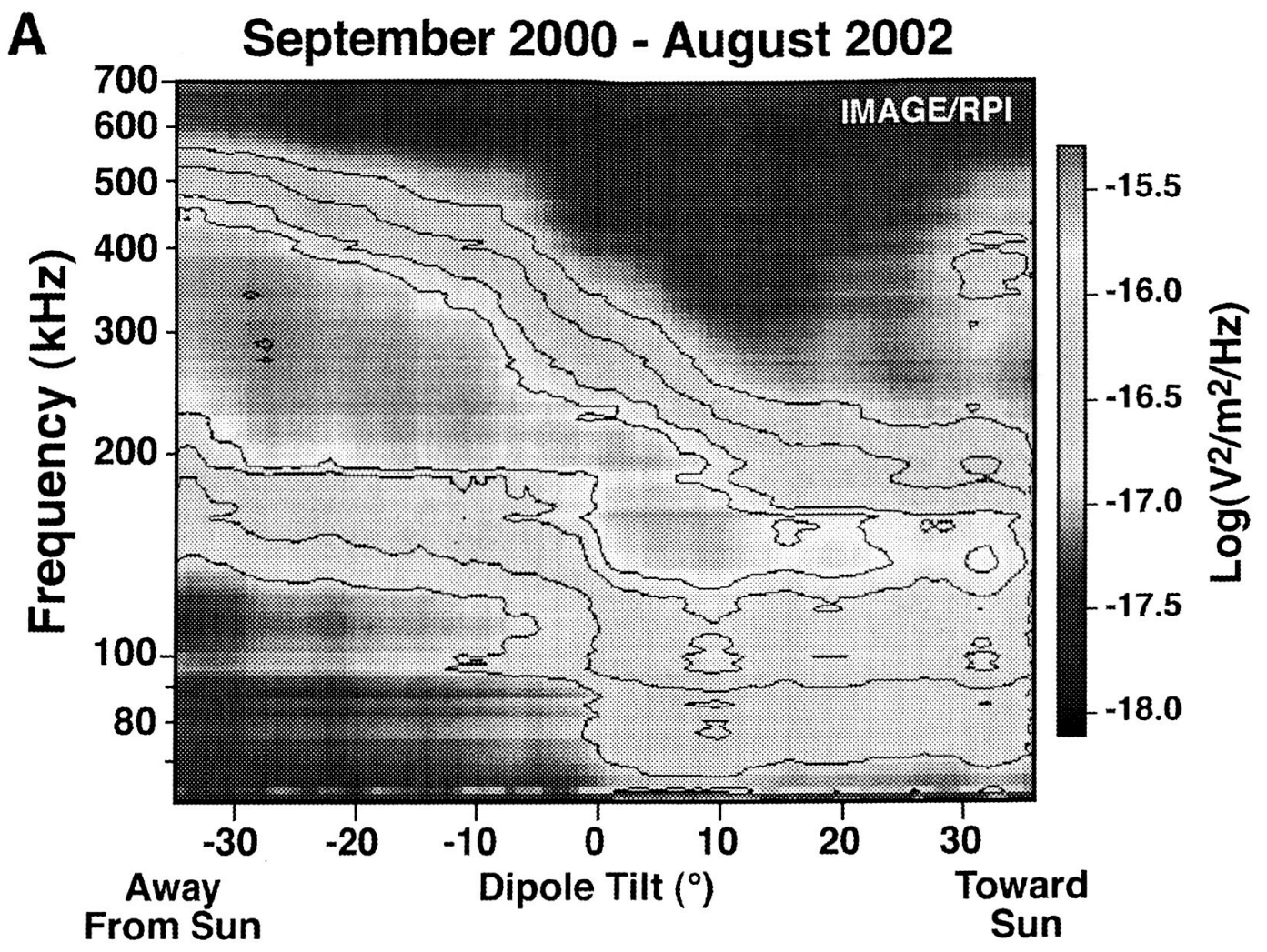

B

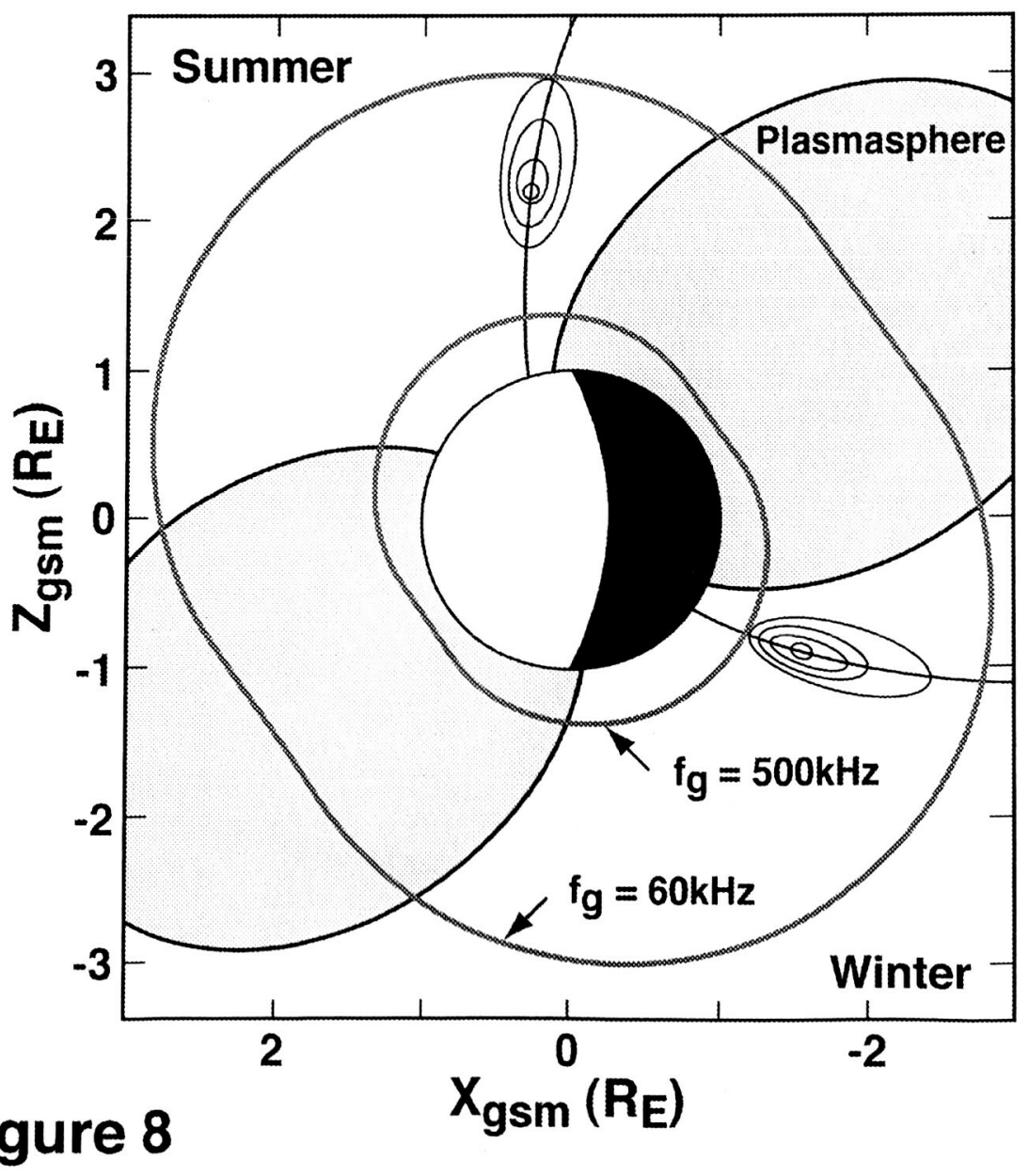

Figure 8 


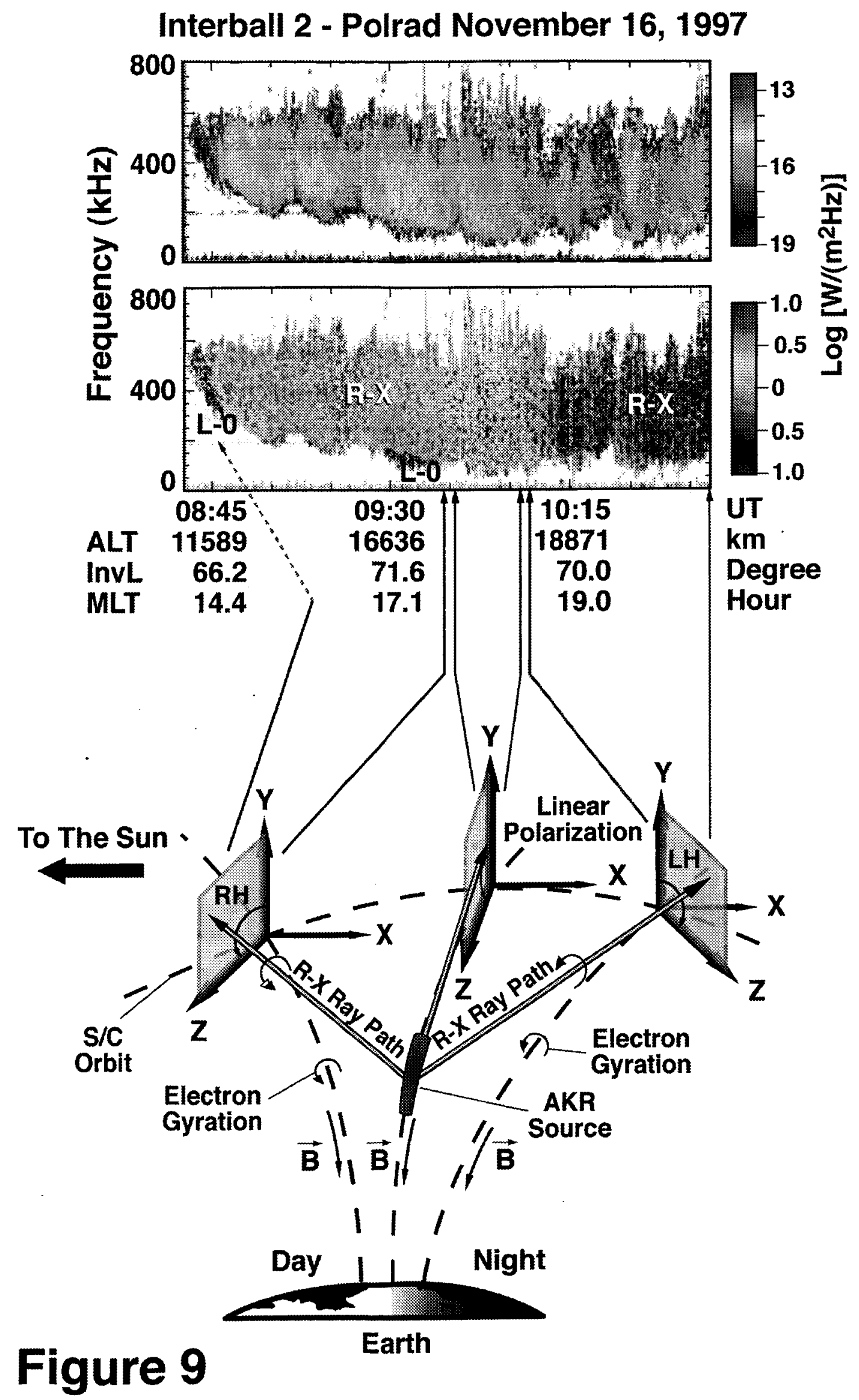



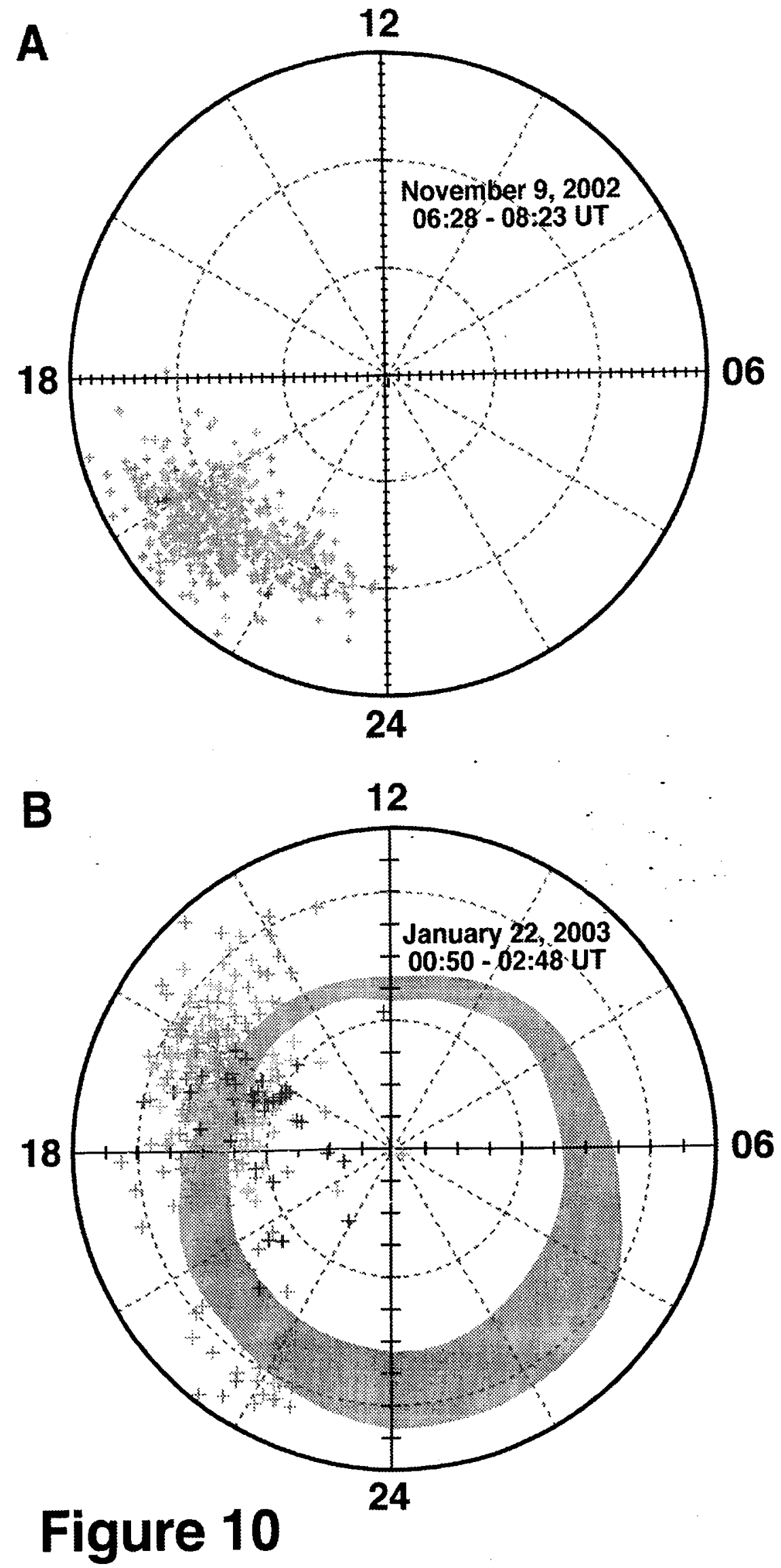







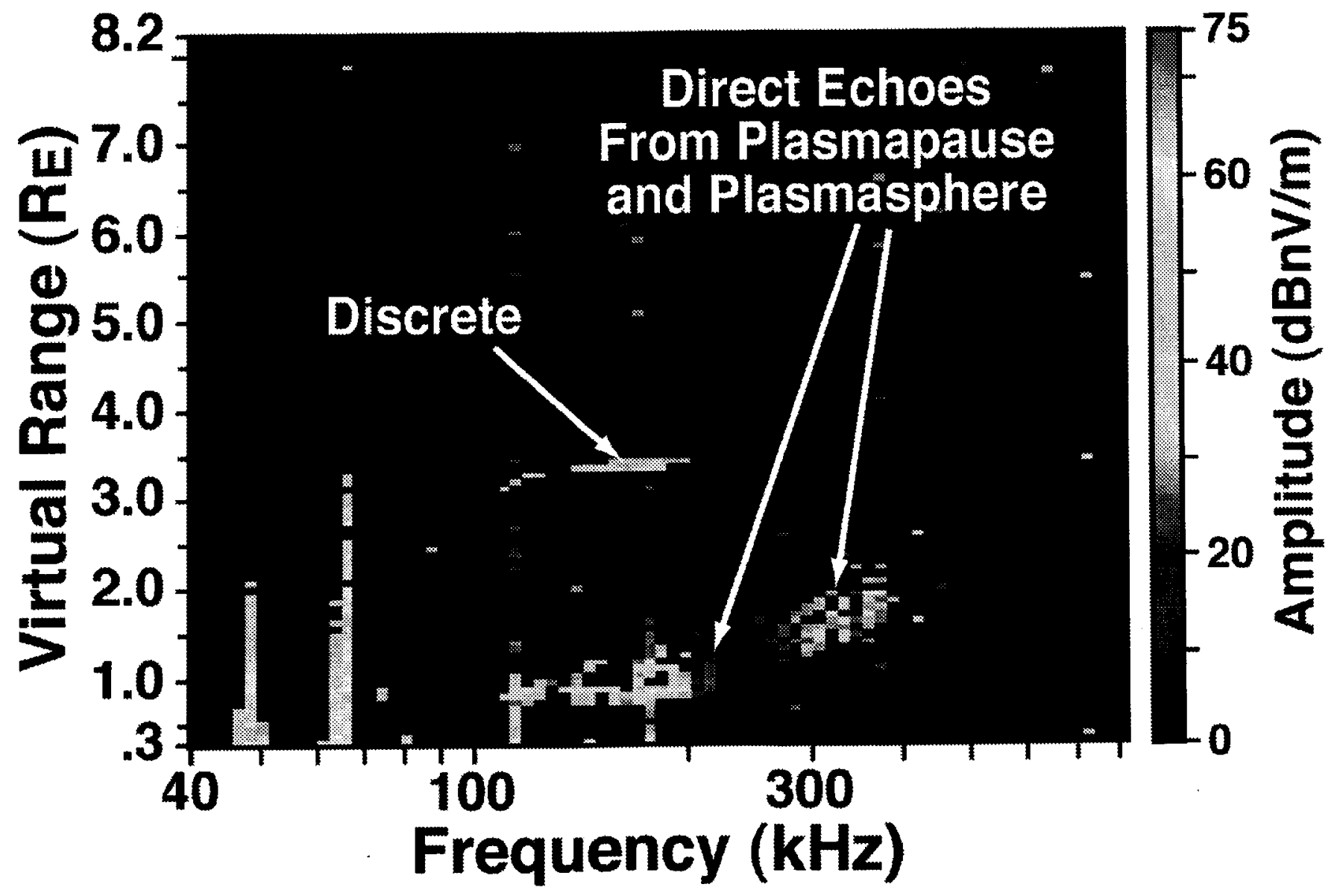

\section{Figure 12}









\section{March 18 10:09:19}

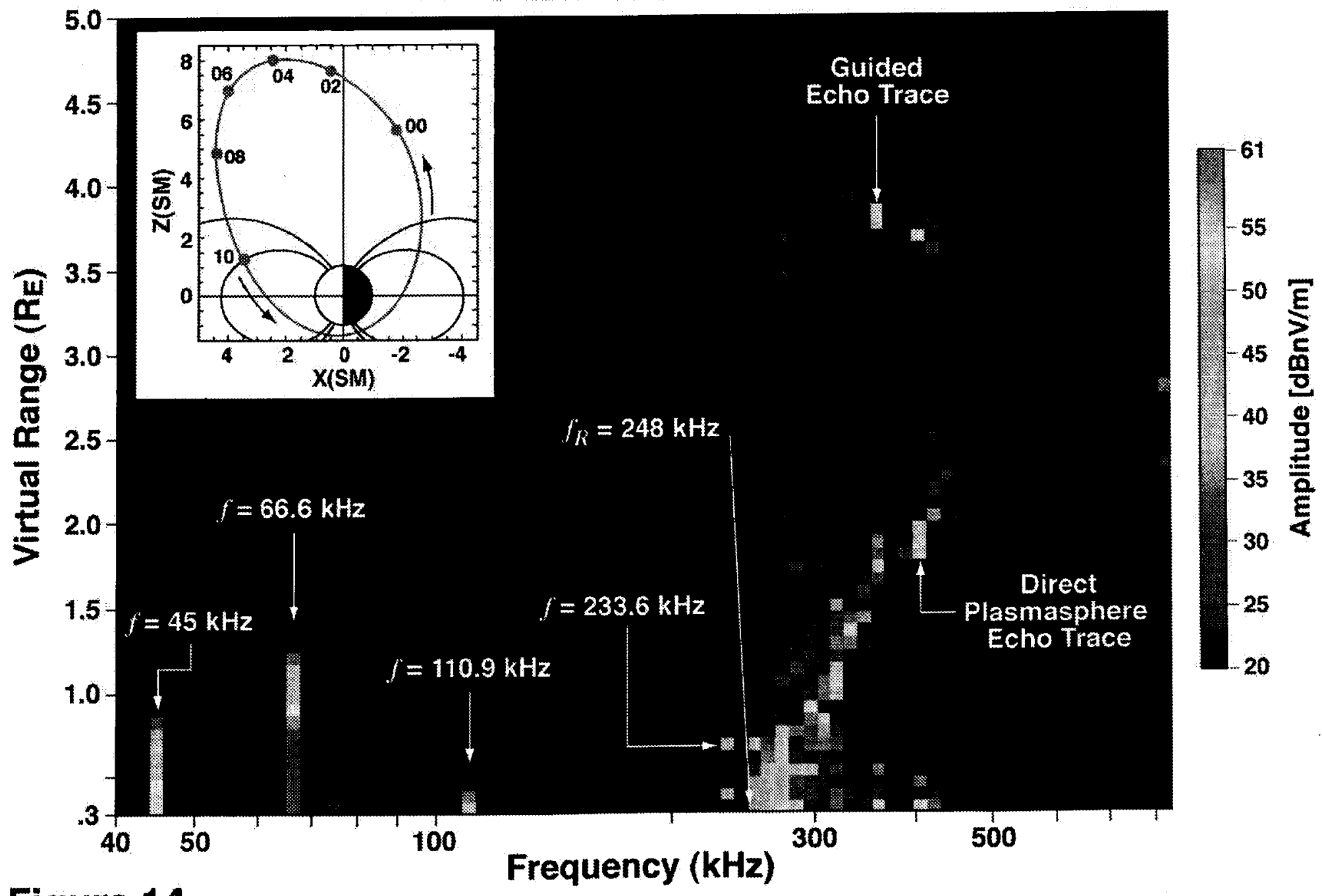

Figure 14 


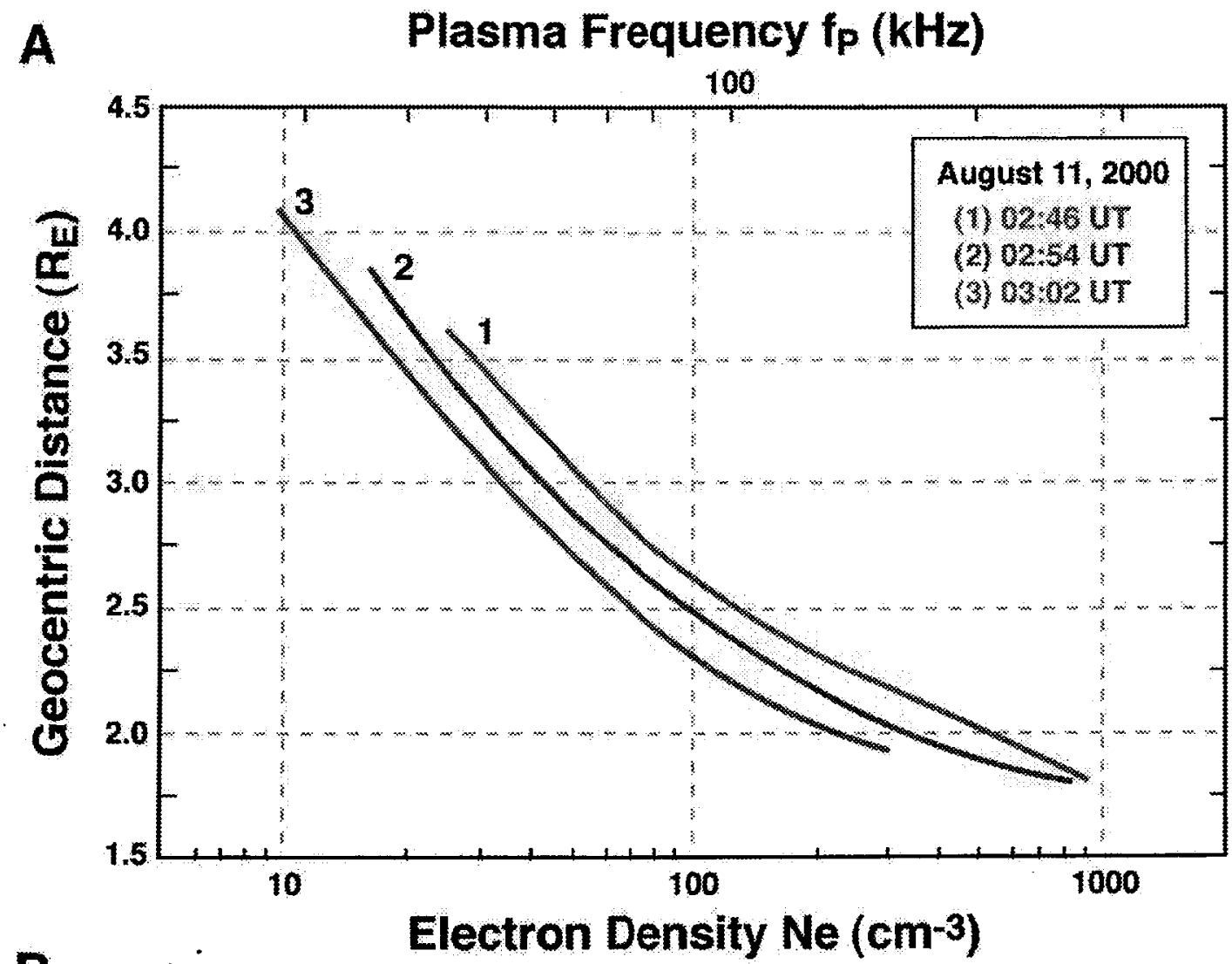

B
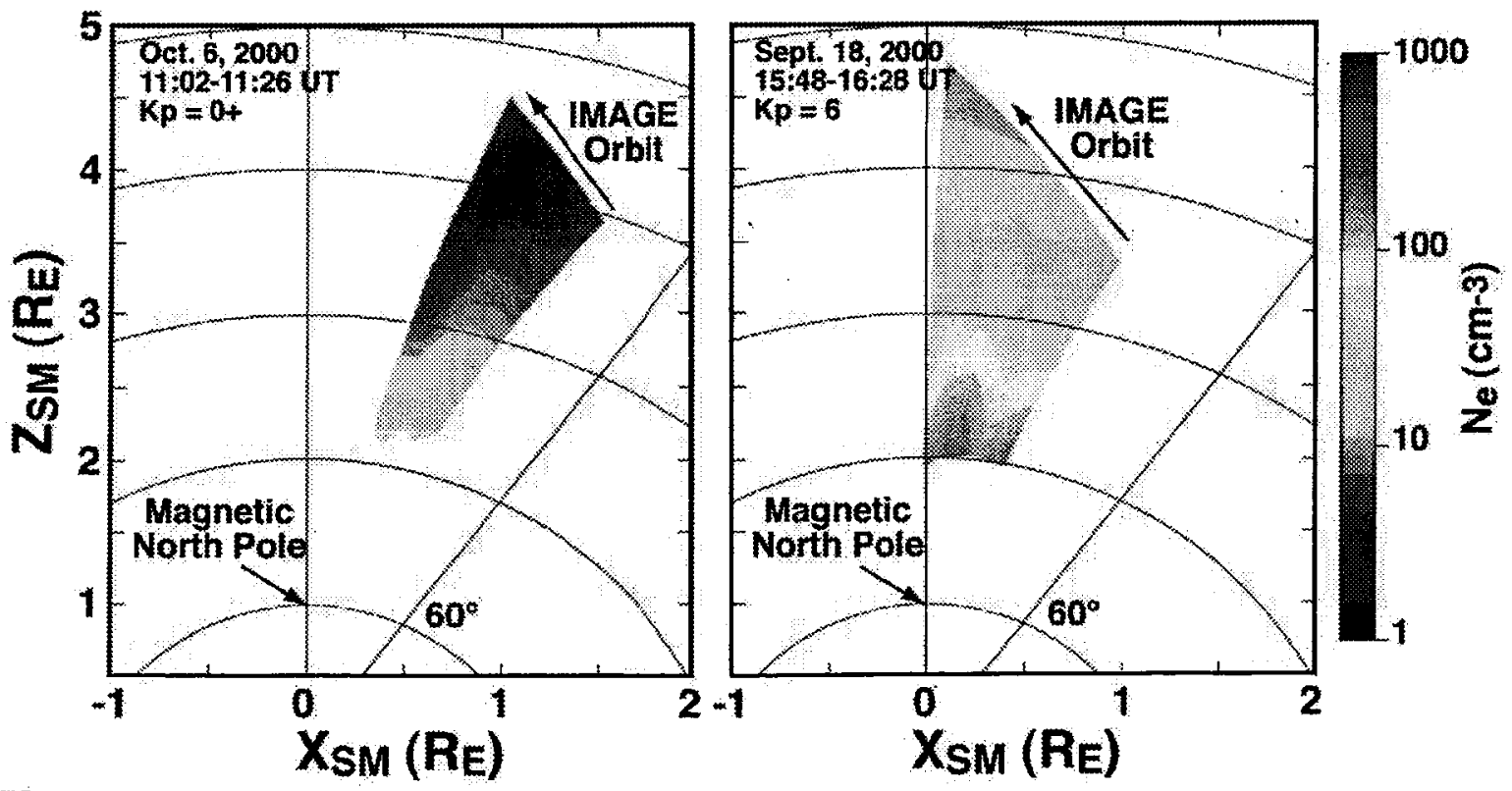

Figure 15 


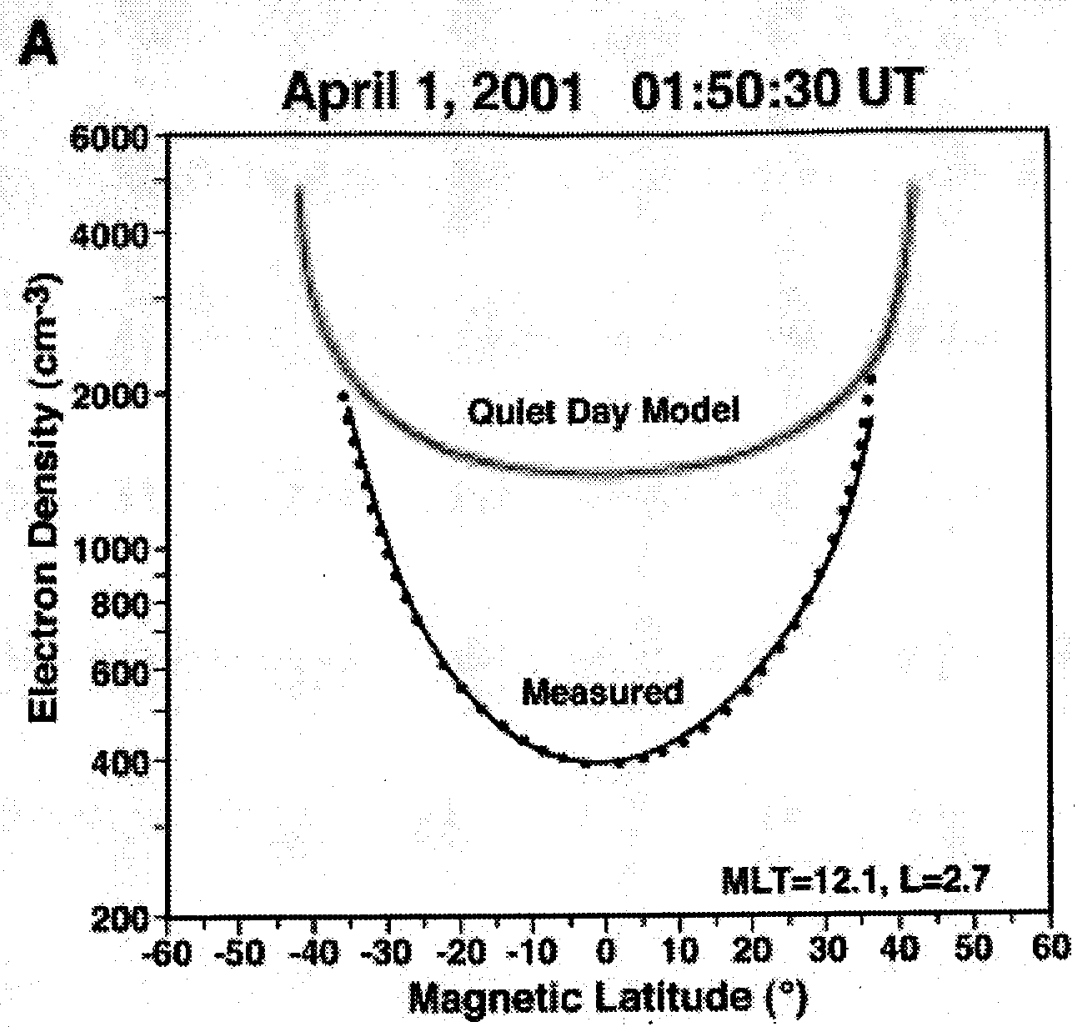

B
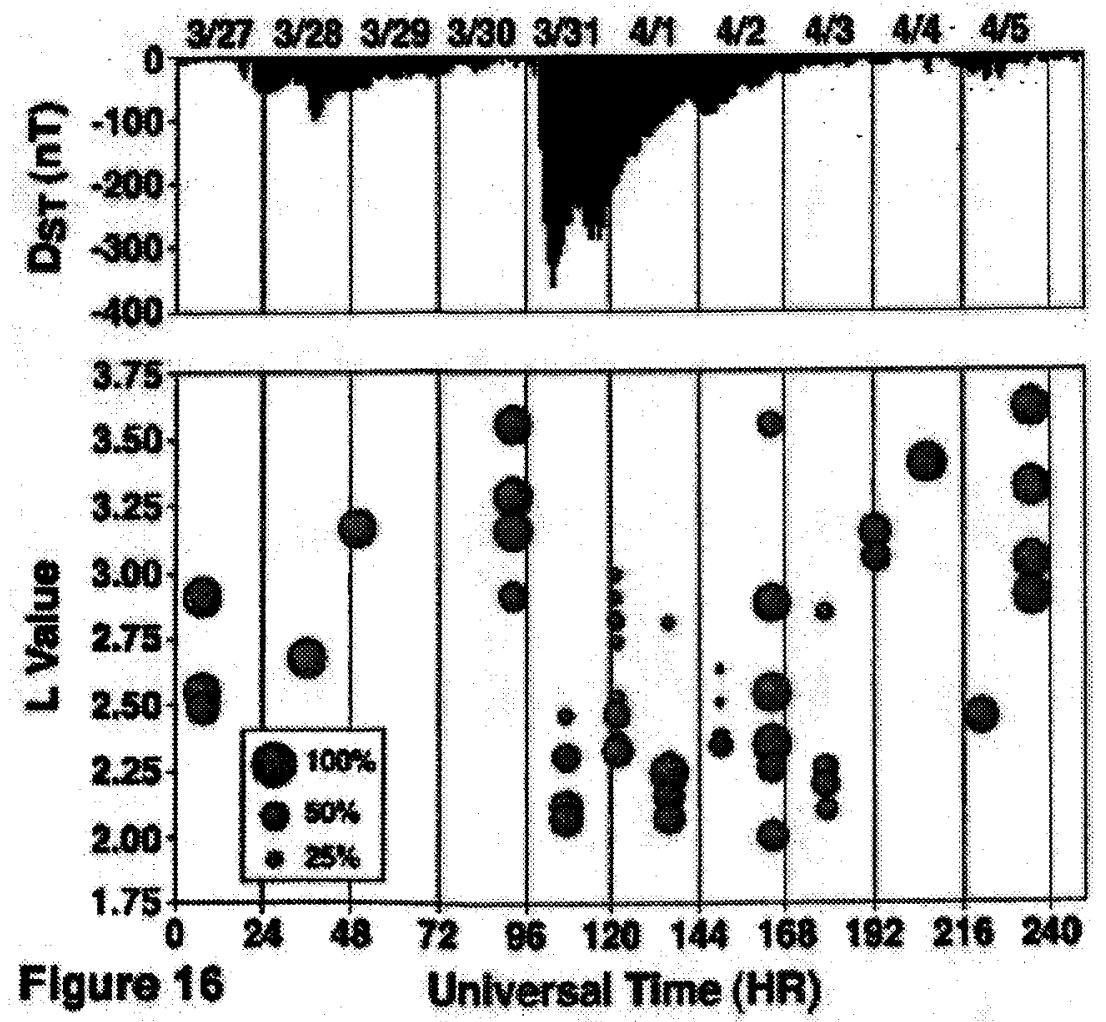